\title{
Removal of Lead, Cadmium, and Aluminum Sulfate from Simulated and Real Water with Native and Oxidized Starches
}

\author{
Konstantin B. L. Borchert ${ }^{1,+}+$, Rahma Boughanmi ${ }^{1,+}$, Berthold Reis ${ }^{1}$, Philipp Zimmermann ${ }^{1}$, \\ Christine Steinbach ${ }^{1}$, Peter Graichen ${ }^{1}$, Anastasiya Svirepa ${ }^{2}$, Johannes Schwarz ${ }^{2}$, Regine Boldt ${ }^{1} \mathbb{D}$, \\ Simona Schwarz ${ }^{1}{ }^{1}$, Michael Mertig ${ }^{2,3}$ and Dana Schwarz ${ }^{1, *}$
}

1 Leibniz-Institut für Polymerforschung Dresden e.V., Hohe Str. 6, 01069 Dresden, Germany; borchert@ipfdd.de (K.B.L.B.); boughanmi@ipfdd.de (R.B.); reis@ipfdd.de (B.R.); zimmermann-philipp@ipfdd.de (P.Z.); steinbach@ipfdd.de (C.S.); graichen@ipfdd.de (P.G.); boldt@ipfdd.de (R.B.); simsch@ipfdd.de (S.S.)

2 Kurt-Schwabe-Institut für Mess-und Sensortechnik Meinsberg e.V., Kurt-Schwabe-Str. 4, 04736 Waldheim, Germany; anastasiya.svirepa@ksi-meinsberg.de (A.S.); johannes.schwarz@ksi-meinsberg.de (J.S.); michael.mertig@tu-dresden.de (M.M.)

3 Institute of Physical Chemistry, Technische Universität Dresden, 01062 Dresden, Germany

* Correspondence: schwarz-dana@ipfdd.de; Tel.: +49-351-46-58-542

$+\quad$ These authors contributed equally to this work.

check for updates

Citation: Borchert, K.B.L.;

Boughanmi, R.; Reis, B.;

Zimmermann, P.; Steinbach, C.; Graichen, P.; Svirepa, A.; Schwarz, J.; Boldt, R.; Schwarz, S.; et al. Removal of Lead, Cadmium, and Aluminum Sulfate from Simulated and Real Water with Native and Oxidized Starches. Polysaccharides 2021, 2, 429-453. https://doi.org/10.3390/ polysaccharides 2020027

Academic Editor: Alessandra Braga Ribeiro

Received: 28 February 2021

Accepted: 26 May 2021

Published: 4 June 2021

Publisher's Note: MDPI stays neutral with regard to jurisdictional claims in published maps and institutional affiliations.

Copyright: (c) 2021 by the authors. Licensee MDPI, Basel, Switzerland. This article is an open access article distributed under the terms and conditions of the Creative Commons Attribution (CC BY) license (https:/ / creativecommons.org/licenses/by/ $4.0 /)$.
Abstract: The separation of toxic pollutants such as $\mathrm{Pb}^{2+}, \mathrm{Cd}^{2+}$, and $\mathrm{Al}^{3+}$ from water is a constant challenge as contamination of natural water bodies is increasing. $\mathrm{Al}^{3+}$ and especially $\mathrm{Pb}^{2+}$ and $\mathrm{Cd}^{2+}$ are ecotoxic and highly toxic for humans, even in ppb concentrations, and therefore removal below a dangerous level is demanding. Herein, the potential adsorber material starch, being ecofriendly, cheap, and abundantly available, was investigated. Thus, four different native starch samples (potato, corn, waxy corn, and wheat starch) and two oxidized starches (oxidized potato and corn starch) were comprehensively analyzed with streaming potential and charge density measurements, SEM-EDX, ATR-FTIR, ${ }^{1} \mathrm{H}-\mathrm{NMR}$, and TGA. Subsequently, the starch samples were tested for the adsorption of $\mathrm{Pb}^{2+}, \mathrm{Cd}^{2+}$, and $\mathrm{Al}^{3+}$ from the respective sulfate salt solution. The adsorption process was analyzed by ICP-OES and SEM-EDX, and the adsorption isotherms were fitted comparing Langmuir, Sips, and Dubinin-Radushkevich models. Oxidized starch, for which chemical modification is one of the simplest, and also native potato starch were excellent natural adsorber materials for $\mathrm{Al}^{3+}, \mathrm{Cd}^{2+}$, and especially $\mathrm{Pb}^{2+}$ in the low concentration range, exhibiting maximum adsorption capacities of 84 , 71 , and $104 \mu \mathrm{mol} / \mathrm{g}$ for oxidized potato starch, respectively.

Keywords: native starch; oxidized starch; heavy metal ion adsorption; water treatment

\section{Introduction}

The amount of environmental contamination and discharges of industrial waste all over the world is increasing at an alarming pace, with a simultaneously growing water demand worldwide [1,2]. The separation of heavy metal ions by technically feasible and cost-efficient adsorber materials is crucial for the water supply of people worldwide, especially in economically weaker countries or for the supply after environmental disasters. Different separation methods can be applied such as ion exchange, membrane filtration, chemical precipitation, electrocoagulation, and reverse osmosis [3]. Yet, these methods are very costly and can be exorbitantly resource-consuming when upscaled to huge factories. Furthermore, these methods partially have negative impacts on nature when used excessively [4]. In order for these problems to be circumvented, adsorption methods using biopolymers can be applied, wherein they feature several advantages as they are biodegradable, renewable, abundant, compostable, and environmentally friendly $[5,6]$. Thus, biopolymers are a better alternative for synthetic adsorber materials since these can pose a risk to the environment with toxic byproducts or educts [7]. The increasing demand 
for environmentally friendly and biodegradable processes for the recovery of metal ions from industrial effluents led many research groups to investigate biomaterials such as chitosan, starch, and pectin [8-10]. Chitosan is a biobased polymer that has been extensively investigated by many research groups as an adsorber material and flocculant for water purification, as ion-complexing compounds in electrochemical sensors, in biomedical applications, or as an additive in paper processing due to its astonishing properties [11-21]. Moreover, other biomaterials such as pectin or starch have been studied as flocculants or as adsorbers for the removal of toxic heavy metal ions [22-24]. However, to enhance the adsorption efficiency of starch, it is often modified in various ways, e.g., by etherification [25], esterification [3], carboxymethylation [26], or hydrogelation [27]. Time- or energy-consuming chemical modifications, especially when including the use of costly or toxic educts, partially counteract the advantage of starch, being itself a low-cost and ecofriendly biopolymer. Therefore, it is important to investigate the ability of unmodified starch or only simple chemical modifications, such as oxidation [28], whereby the ecologic and economic advantages of this 'green' adsorber material are not outweighed.

Highly toxic and abundantly used heavy metal ions, such as $\mathrm{Pb}^{2+}$ and $\mathrm{Cd}^{2+}$, pollute natural water bodies worldwide through progressing industrialization. The pollution by $\mathrm{Pb}^{2+}$ can be caused by mining, battery production, and metal processing $[1,2,29,30]$. Bioaccumulation of lead at ppm or ppb levels can cause severe damage in, e.g., metabolism, hematopoiesis, and the nervous system of all exposed living organisms, including humans, leading to death [29,31-37]. $\mathrm{Cd}^{2+}$ is mainly released to the environment by fertilizer and battery production and the semiconductor industry [1,2,30,38-40]. In the environment, $\mathrm{Cd}^{2+}$ in low concentrations can pose a risk to marine and freshwater aquatic life in the form of, e.g., genotoxicity and liver and kidney degeneration [38,41]. Therefore, $\mathrm{Cd}^{2+}$ is classified as carcinogenic in addition to lowering bone density in humans and severe renal damage $[42,43]$. In addition to weathering of minerals, $\mathrm{Al}^{3+}$ enters the aquatic ecosystems from anthropogenic activities such as waste disposal and the metal-producing industry, and is still widely applied for water treatment as cheap flocculant [44-48]. Aluminum, although not being a heavy metal, is harmful for humans as it is highly cytotoxic since it causes oxidative stress and alters enzymatic activity [48]. Furthermore, $\mathrm{Al}^{3+}$ is toxic for algae, fish, and invertebrates due its acidity [45,49]. Thus, the sufficient removal of these metal ions below a dangerous concentration is still a crucial problem. The adsorption of $\mathrm{Al}^{3+}$ on starch has been reported by Choksi et al. by using $\mathrm{AlCl}_{3}$ at nearly neutral initial $\mathrm{pH}$ values of 6.0 to 8.5 [50].

Here, we show the first study on the adsorption of $\mathrm{Al}_{2}\left(\mathrm{SO}_{4}\right)_{3}$ on different native and oxidized starch samples at $\mathrm{pH} 4.2$ and 3.4 using simulated and real water samples, respectively. We investigated different native starches (i.e., potato starch, corn starch, waxy corn starch, and wheat starch) and oxidized starches (i.e., oxidized potato starch and oxidized corn starch), representing the simplest chemical modification, for the adsorption of $\mathrm{Al}^{3+}, \mathrm{Cd}^{2+}, \mathrm{Pb}^{2+}$, and $\mathrm{SO}_{4}{ }^{2-}$ from $\mathrm{Al}_{2}\left(\mathrm{SO}_{4}\right)_{3}, \mathrm{CdSO}_{4}$, and $\mathrm{PbSO}_{4}$ solutions. To compare the adsorption properties of these different starches, we comprehensively characterized the samples by laser diffractometry, SEM-EDX, ${ }^{1} \mathrm{H}-\mathrm{NMR}$, ATR-FTIR spectroscopy, TGA, moisture analysis, and ICP-OES. We compared the adsorption performance of native and oxidized starches for $\mathrm{Al}^{3+}, \mathrm{Cd}^{2+}, \mathrm{Pb}^{2+}$, and sulfate at concentrations in the lower ppm range. On the basis of the adsorption performance at low concentrations, we further investigated $\mathrm{n}$. potato starch as the best performing native starch for the adsorption of $\mathrm{Al}^{3+}, \mathrm{Cd}^{2+}$, and $\mathrm{Pb}^{2+}$ and $\mathrm{n}$. corn starch as a reference, together with the corresponding oxidized starches. The kinetics and adsorption mechanism of the samples were discussed on the basis of the sorption isotherms measured with ICP-OES and further characterized by SEM-EDX imaging and spectroscopy. 


\section{Materials and Methods}

\subsection{Materials}

Starch samples: Different starch samples, namely, native potato starch (Agrana sample number A4757), native corn starch (Agrana sample number A4758), native waxy corn starch (Agrana sample number A4759), native wheat starch (Agrana sample number A4760), oxidized corn starch (Agrana sample number A4761), and oxidized potato starch (Agrana sample number A4762) were received as powder from AGRANA Research and Innovation Center GmbH, Tulln, Austria. The starch samples were characterized and used without further purification.

For simplification, we have abbreviated the native starches with "n." and the oxidized starches with "o." in figures.

Ultrapure water purified by a Milli-Q Advantage A10 ${ }^{\circledR}$ system (Millipore, Darmstadt, Germany) (total organic carbon $=5 \mathrm{ppb}$, resistivity of $18.2 \mathrm{M} \Omega \mathrm{cm}$ ) was used for all experiments.

Heavy metal salts: For the sorption experiments, $\mathrm{PbSO}_{4}(98 \%)$ (Sigma-Aldrich, München, Germany), $\mathrm{CdSO}_{4} \cdot \mathrm{H}_{2} \mathrm{O}$ (p.a.) (Merck, Darmstadt, Germany), and $\mathrm{Al}_{2}\left(\mathrm{SO}_{4}\right)_{3}$ (p.a.) (SigmaAldrich, München, Germany) were used as received without further purification.

ICP-OES standard solutions: For the ICP-OES measurements, the following standards were used: 10,008 mg/L Pb in 5 wt \% $\mathrm{HNO}_{3}$ (Sigma-Aldrich, München, Germany), $10,000 \mathrm{mg} / \mathrm{L} \mathrm{Cd}$ in $2 \mathrm{~mol} / \mathrm{L} \mathrm{HNO}_{3}$ (Bernd Kraft, Duisburg, Germany), 10,000 mg/L Al in $2 \mathrm{~mol} / \mathrm{L} \mathrm{HNO}_{3}$ (Bernd Kraft, Duisburg, Germany), 10,000 mg/L P in water (Bernd Kraft, Duisburg, Germany), 9998 mg/L S in water (Sigma-Aldrich, München, Germany), 10,000 mg/L $\mathrm{Ca}$ in $4 \mathrm{wt} \% \mathrm{HNO}_{3}$ (CPI International, Santa Rosa, CA, USA), 10,000 mg/L Na in 3 wt \% $\mathrm{HNO}_{3}$ (CPI International, Santa Rosa, CA, USA), 10,000 mg/L K in 1 wt \% $\mathrm{HNO}_{3}(\mathrm{CPI}$ International, Santa Rosa, CA, USA), and 10,000 mg/L Si in $\mathrm{H}_{2} \mathrm{O}$ (CPI International, Santa Rosa, CA, USA).

\subsection{Methods}

Charge density was measured with the particle charge detector MÜTEK PCD-04 from the company BTG Instruments $\mathrm{GmbH}$ in Wessling, Germany. A total of $25 \mathrm{~g}$ of the starch samples were added to $500 \mathrm{~mL}$ of ultrapure water. The $\mathrm{pH}$ of the dispersion was then adjusted with $0.1 \mathrm{~m} / \mathrm{L} \mathrm{NaOH}$ or $0.1 \mathrm{~mol} / \mathrm{L} \mathrm{HCl}$ solution to reach $\mathrm{pH}$ values of 3, 5, and 9 . The samples were titrated against a poly(diallyldimethylammonium chloride) (PDADMAC) or a polyethylensulfonate (PES-Na) solution with a concentration of $0.001 \mathrm{~mol} / \mathrm{L}$ until the point of zero charge was reached. A total of $10 \mathrm{~mL}$ of the real water samples were also titrated this way.

Streaming potential vs. $\mathbf{p H}$ curves were measured to determine the starch surface charge in dependence of the $\mathrm{pH}$. Moreover, the real water samples were analyzed. The samples were characterized by titration to $\mathrm{pH} 3$ and 9 from the initial $\mathrm{pH}$ with the particle charge detector MÜTEK PCD-04 from the company BTG Instruments GmbH. For this purpose, we added $0.5 \mathrm{~g}$ of the native starch powders or $0.1 \mathrm{~g}$ of the oxidized starch samples to $15 \mathrm{~mL}$ of ultrapure water. From the real water samples, $15 \mathrm{~mL}$ was measured without dilution. The samples were titrated against a $0.1 \mathrm{~m} / \mathrm{L} \mathrm{NaOH}$ or $0.1 \mathrm{~mol} / \mathrm{L} \mathrm{HCl}$ solution, depending on the desired $\mathrm{pH}$ range.

Moisture analysis of the starch samples and the real water samples were carried out at $110{ }^{\circ} \mathrm{C}$ with the Halogen Moisture Analyzer HX204 from Mettler Toledo, Gießen, Germany. These results were taken into account for the adsorption experiments.

Solubility determination was carried out by stirring $0.1 \mathrm{~g}$ of the respective starch sample in $50 \mathrm{~mL}$ of ultrapure water. The suspension was stirred for $24 \mathrm{~h}$ at $400 \mathrm{rpm}$ at room temperature. The solubility was visually assessed. Furthermore, the particle size distributions were measured after $0 \mathrm{~min}$ and $24 \mathrm{~h}$ in water (see particle size measurement).

Scanning electron microscope (SEM): Different samples were analyzed using a SEM Ultra Plus from Carl Zeiss Microscopy GmbH, Oberkochen, Germany. For this purpose, the samples were fixed with double-sided adhesive carbon tape on an aluminum pin sample 
tray and afterwards streamed with $\mathrm{N}_{2}$ to obtain only a thin layer of particles. The samples were then sputtered with $3 \mathrm{~nm}$ of platinum using a Sputter Coater SCD050 from Leica Microsystems, Wetzlar, Germany, before the investigation started. The measurements were carried out with an acceleration voltage of $3 \mathrm{keV}$ at different magnifications.

Scanning electron microscope with energy-dispersive X-ray spectroscopy (SEMEDX): Different samples were analyzed using a scanning electron microscope (SEM Ultra Plus, Carl Zeiss Microscopy GmbH, Jena, Germany), equipped with an energy-dispersive Xray spectroscopy detector (EDX XFlash Quad 5060F, Bruker Nano GmbH, Berlin, Germany). For the measurement of inorganic impurities, the samples were fixed with double-sided adhesive carbon tape on an aluminum pin sample tray and covered with carbon before the investigation starts. The measurements were carried out with an acceleration voltage of $6 \mathrm{keV}$ at different magnifications. In some instances, for the qualification of trace elements, we measured maximum pixel spectra, as also stated in the respective graphs.

The elemental mapping of the samples after the adsorption experiments by SEMEDX was carried out using a Phenom XL Workstation from Thermo Scientific (Waltham, USA) with an energy-dispersive X-ray spectroscopy (EDX) detector (Silicon Drift Detector SDD, thermoelectrically cooled (LN2free), $25 \mathrm{~mm}^{2}$ detector active area). The samples were fixed on a double-sided adhesive carbon tape on an aluminum pin sample tray. The measurements were carried out in low-vacuum mode $(p=60 \mathrm{~Pa})$ with an acceleration voltage of $15 \mathrm{keV}$ at different magnifications.

ATR-FTIR spectra were acquired with a Tensor 27 device equipped with a Platinum ATR module, both from Bruker Corporation, Billerica, MA, USA. The samples were measured in dry state with a resolution of $2 \mathrm{~cm}^{-1}$ and with 100 scans.

The particle size distributions of the dispersed particles in ultrapure water were determined with the Mastersizer Microplus device from Malvern Panalytical GmbH, Kassel Germany. For the measurements without swelling time, the dry particles were directly added into the dispersion chamber and subsequently measured. For the measurement of the particles in swollen state, $5 \mathrm{~g}$ of the starch samples were placed in $100 \mathrm{~mL}$ water and were allowed to swell for $24 \mathrm{~h}$ under stirring. Afterwards, they were added to the dispersion chamber and subsequently measured. For evaluation, the 5OFD model was chosen, with 1.5295 as the refractive index of starch, 0.01 as absorption value for starch, and 1.33 as refractive index of water.

In dry state, the particle sizes were measured using the device BlueWave from Microtrac, Meerbusch, Germany. As a model, aspherical particles were assumed and 1.5295 was taken as refractive index.

Elemental analysis was carried out using a vario MICRO cube from the company Elementar, Langenselbold, Germany.

Nitrogen sorption measurements were performed using the Autosorb iQ MP from Quantachrome Instruments (Boynton Beach, FL, USA). First, the samples were dried in a vacuum oven at $100{ }^{\circ} \mathrm{C}$. The samples were activated by degassing in vacuum $\left(5 \times 10^{-10} \mathrm{mbar}\right)$ at $90^{\circ} \mathrm{C}$. The nitrogen sorption measurements were performed at $77 \mathrm{~K}$.

Carbon dioxide sorption measurements were performed using the Autosorb iQ MP from Quantachrome Instruments (Boynton Beach, FL, USA). First, the samples were dried in a vacuum oven at $100{ }^{\circ} \mathrm{C}$. The samples were activated by degassing in vacuum $\left(5 \times 10^{-10} \mathrm{mbar}\right)$ at $90^{\circ} \mathrm{C}$. The carbon dioxide sorption measurements were performed at $273 \mathrm{~K}$.

Inductively Coupled Plasma Optical Emission Spectrometry (ICP-OES) (iCAP 7400 from Thermo Scientific, Waltham, MA, USA) was used to determine

- the heavy metal ion and sulfate ion concentrations in simulated wastewater. Thus, 5 standards were used: Standard 1: S (100 mg/L); Standard 2: $\mathrm{Pb}, \mathrm{Al}, \mathrm{Cd}$, and S (each $50 \mathrm{mg} / \mathrm{L}$ ), Standard 3: $\mathrm{Pb}, \mathrm{Al}, \mathrm{Cd}$, and S (each $10 \mathrm{mg} / \mathrm{L}$ ), Standard 4: Pb, Al, Cd, and $\mathrm{S}$ (each $5 \mathrm{mg} / \mathrm{L}$ ), Standard 5: $\mathrm{Pb}, \mathrm{Al}, \mathrm{Cd}$, and $\mathrm{S}$ (each $1 \mathrm{mg} / \mathrm{L}$ ), Standard 6: Pb, Al, $\mathrm{Cd}$, and $\mathrm{S}$ (each $0.5 \mathrm{mg} / \mathrm{L}$ ). Each standard contained $4 \mathrm{wt} \% \mathrm{HNO}_{3}$. To each sample of $8 \mathrm{~mL}$, we added $2 \mathrm{~mL}$ of $20 \mathrm{wt} \%$ nitric acid prior to analysis. From the threefold 
measurement of all standards, we constructed a calibration curve. All samples were measured three times. The detection limits in the measurement solutions were given with $0.05 \mathrm{mg} / \mathrm{L} \mathrm{Al}, 0.01 \mathrm{mg} / \mathrm{L} \mathrm{Cd}, 0.05 \mathrm{mg} / \mathrm{L} \mathrm{Pb}$, and $0.06 \mathrm{mg} / \mathrm{L} \mathrm{S}$.

- potential inorganic impurities in the starch samples. First, $100 \mathrm{mg}$ of each sample was digested by $3.5 \mathrm{~mL}^{2} \mathrm{M} \mathrm{HNO}_{3}$ and $0.5 \mathrm{~mL} 30 \mathrm{wt} \% \mathrm{H}_{2} \mathrm{O}_{2}$ in a $10 \mathrm{~mL} \mathrm{mi-}$ crowave vessel using a Discover SP microwave oven (CEM Corporation, Matthews, NC, USA) in a two-step dynamic, pressurized process (first step: $50 \mathrm{~W}$ max. $/ 85^{\circ} \mathrm{C}$ max./17 bar max./5 min/high magnetic stirring; depressurizing; second step: $100 \mathrm{~W}$ max. $/ 100{ }^{\circ} \mathrm{C}$ max. $/ 17$ bar max. $/ 5 \mathrm{~min} /$ high magnetic stirring) (modified method from Gonzalez et. al. [51]). Afterwards, the sample was quantitatively transferred into a $50 \mathrm{~mL}$ measuring flask with water and filled up to a total volume of $50 \mathrm{~mL}$. The sample was shaken for $24 \mathrm{~h}$. To each ICP-OES sample of $8 \mathrm{~mL}$, we added $2 \mathrm{~mL}$ of 12 wt \% $\mathrm{HNO}_{3}$. The following standards were used: Standard 1: $\mathrm{Ca}, \mathrm{Na}, \mathrm{K}, \mathrm{S}, \mathrm{P}$, and Si (each $500 \mathrm{mg} / \mathrm{L}$ ); Standard 2: Ca, Na, K, S, P, and Si (each $100 \mathrm{mg} / \mathrm{L}$ ); Standard 3: Ca, $\mathrm{Na}, \mathrm{K}, \mathrm{S}, \mathrm{P}$, and Si (each $50 \mathrm{mg} / \mathrm{L}$ ); Standard 4: Ca, Na, K, S, P, and Si (each $10 \mathrm{mg} / \mathrm{L}$ ); Standard 1: Ca, Na, K, S, P, and Si (each $5 \mathrm{mg} / \mathrm{L}$ ); Standard 5: Ca, Na, K, S, P, and Si (each $1 \mathrm{mg} / \mathrm{L}$ ). Each standard contained $4 \mathrm{wt} \% \mathrm{HNO}_{3}$. From the threefold measurement of all standards, we constructed a calibration curve. All samples were measured three times. The given detection limits were calculated by the software Qtegra ${ }^{\mathrm{TM}}$ from Thermo Scientific, Waltham, MA, USA. The detection limits in the measurement solutions were given with $0.05 \mathrm{mg} / \mathrm{L} \mathrm{Ca}, 0.09 \mathrm{mg} / \mathrm{L} \mathrm{Na}, 0.55 \mathrm{mg} / \mathrm{L} \mathrm{K}, 0.14 \mathrm{mg} / \mathrm{L} \mathrm{S}$, $0.05 \mathrm{mg} / \mathrm{L} \mathrm{P}$, and $0.03 \mathrm{mg} / \mathrm{L}$ for Si.

Of the many measured wavelengths, the ones with a low standard deviation and no interferences were chosen.

${ }^{1}$ H-NMR spectroscopy was conducted by using the device Avance III 500 from Bruker Corporation, Billerica, MA, USA, at $500 \mathrm{MHz}$ and $25^{\circ} \mathrm{C}$. A total of $10 \mathrm{mg}$ of the starch samples was added to a mixture of $0.5 \mathrm{~mL}$ deuterated dimethyl sulfoxide (DMSO-d6) (99.5 atom \% deuterated) from Sigma-Aldrich, München, Germany, and $0.12 \mathrm{~mL} \mathrm{D}_{2} \mathrm{O}$ (99.98 atom \% deuterated) from Chemotrade, Düsseldorf, Germany, and afterwards heated to $90{ }^{\circ} \mathrm{C}$ for $15 \mathrm{~min}$.

The branching degree $(\mathrm{BD} \%)$ was calculated using the equation proposed by Gunilla et al. [52]. Thereby the integral H1 hydrogen from the $\alpha-1,6$ glycosidic linkage (branching units) is referenced to the total integral of hydrogens from this position including linear $\left(\alpha-1,4\right.$ glycosidic linkage $\left.=\mathrm{H} 1_{(1-4)}\right)$, branching $\left(\mathrm{H} 1_{(1-6)}\right)$, and terminal $\left(\mathrm{H} 1_{(\mathrm{t})}\right)$ units.

$$
\mathrm{BD} \%=\frac{\text { Integral } \mathrm{H} 1_{(1-6)}}{\text { Integral } \mathrm{H} 1_{(1-6)}+\mathrm{H}_{(1-4)}+\mathrm{H} 1_{(\mathrm{t})}} \cdot 100 \%
$$

Thermogravimetric analysis (TG) was performed by using the device 1 Star System from Mettler Toledo, Gießen, Germany. The measurements were carried out with approximately 7 to $8 \mathrm{mg}$ of starch in a platinum crucible. The investigated temperature range was from $25^{\circ} \mathrm{C}$ to $1000{ }^{\circ} \mathrm{C}$ with a heating rate of $10^{\circ} \mathrm{C} / \mathrm{min}$ under air and $\mathrm{N}_{2}$ atmosphere with a flow rate of $40 \mathrm{~mL} / \mathrm{min}$.

pH and conductivity measurements were conducted with the device SevenExcellence $^{\mathrm{TM}}$ from Mettler Toledo, Gießen, Germany.

\subsection{Adsorption Experiments}

\subsubsection{Simulated Water Samples}

Stock solutions of each heavy metal salt $\left(\mathrm{Al}_{2}\left(\mathrm{SO}_{4}\right)_{3}, \mathrm{CdSO}_{4}\right.$, or $\left.\mathrm{PbSO}_{4}\right)$ were prepared in $500 \mathrm{~mL}$ volumetric flasks with $50 \mathrm{mg} / \mathrm{L} \mathrm{Al}^{3+}, 50 \mathrm{mg} / \mathrm{L} \mathrm{Cd}^{2+}$, or $40 \mathrm{mg} / \mathrm{L} \mathrm{Pb}^{2+}$, respectively. For the adsorption experiments, these were diluted to targeted metal ion concentrations ranging from 0.1 to $50 \mathrm{mg} / \mathrm{L}$. For $\mathrm{PbSO}_{4(\mathrm{aq})}$, solutions with a maximum concentration of $40 \mathrm{mg} / \mathrm{L}$ were prepared due to the solubility limit of lead sulfate. The salts were dissolved in ultrapure water. The $\mathrm{pH}$ of the resulting solutions was not adjusted. 
For the adsorption experiments, $100 \mathrm{mg}$ starch was placed into a $50 \mathrm{~mL}$ centrifuge tube. Subsequently, $30 \mathrm{~mL}$ of the respective heavy metal ion solution was added. The samples were stirred for two hours with a magnetic stirrer. After the centrifugation $(11,000 \mathrm{rpm}$ for $8 \mathrm{~min}$ ), the $\mathrm{pH}$ of the supernatant was analyzed. A total of $8 \mathrm{~mL}$ of the supernatant was taken and mixed with $2 \mathrm{~mL}$ of $20 \mathrm{wt} \%$ nitric acid for ICP-OES analysis. To determine the adsorption capacity experimentally with $\mathrm{PbSO}_{4}$, we later used only $10 \mathrm{mg}$ of starch instead of $100 \mathrm{mg}$ due to the limited solubility of $\mathrm{PbSO}_{4}$.

\subsubsection{Real Water Samples}

Three real water samples were taken from three different spots at the Vincenzgraben in Germany. The $\mathrm{pH}$ and the electrical conductivity were measured. For the adsorption experiments, $100 \mathrm{mg}$ starch was placed into a $50 \mathrm{~mL}$ centrifuge tube. For the adsorption experiment with water 1,30 $\mathrm{mL}$ of the real water sample was added. The sample was stirred for two hours. For the adsorption experiments with water 2 and water 3, $15 \mathrm{~mL}$ ultrapure water was added first. After $24 \mathrm{~h}, 15 \mathrm{~mL}$ of the real water samples was added. The samples were stirred for $24 \mathrm{~h}$ with a magnetic stirrer. After the centrifugation (11,000 rpm for $8 \mathrm{~min})$, the $\mathrm{pH}$ of all supernatants was analyzed. A total of $8 \mathrm{~mL}$ of the supernatants was taken and mixed with $2 \mathrm{~mL}$ of $20 \mathrm{wt} \%$ nitric acid for ICP-OES analysis.

To evaluate potential errors by contained solids or dissolved organic matter, we processed a control sample containing only the real water sample without starch in the same way as the adsorption samples, which was subsequently analyzed. The initial ion concentration of the unprocessed water sample and the control sample itself were taken as upper and lower error limits, respectively. The mean value of both was taken as the initial concentration for the calculation of the adsorption.

\subsection{Theoretical Model}

To determine the sorption efficiency of the starches, we detected the concentration of the adsorbed metal ions and sulfate ions in equilibrium by ICP-OES, which was used in Equation (2), where the calculation of the sorption as a percentage can be seen with $\mathrm{c}_{0}$ as the concentration of the respective ion in the initial solution and $\mathrm{c}_{\mathrm{eq}}$ as the concentration after reaching equilibrium.

$$
\text { adsorption }(\%)=100 \cdot \frac{\mathrm{c}_{0}-\mathrm{c}_{\mathrm{eq}}}{\mathrm{c}_{0}}
$$

The respective sorption capacity $q$ in equilibrium was calculated as follows:

$$
\mathrm{q}_{\mathrm{eq}}=\frac{\left(\mathrm{c}_{0}-\mathrm{c}_{\mathrm{eq}}\right) \cdot \mathrm{V}_{\mathrm{L}}}{\mathrm{m}_{\mathrm{A}}}
$$

with $\mathrm{V}_{\mathrm{L}}$ referring to the given volume of the adsorptive solution and $\mathrm{m}_{\mathrm{A}}$ to the mass of the sorbent material used in the experiment.

To model the sorption process, we used different fitting models, as there were Langmuir (Equation (4) [53], Sips (Equation (5)) [54] and Dubinin-Radushkevich (Equations (6)-(8)) [55] models.

Langmuir model

$$
\mathrm{q}_{\mathrm{eq}}=\frac{\mathrm{Q}_{\mathrm{m}} \cdot \mathrm{K}_{\mathrm{L}} \cdot \mathrm{c}_{\mathrm{eq}}}{1+\mathrm{K}_{\text {Langmuir }} \cdot \mathrm{c}_{\mathrm{eq}}}
$$

Sips model

$$
\mathrm{q}_{\mathrm{eq}}=\frac{\mathrm{Q}_{\mathrm{m}} \cdot \mathrm{K}_{\mathrm{S}} \cdot \mathrm{c}_{\mathrm{eq}}^{\mathrm{n}}}{1+\mathrm{K}_{\mathrm{S}} \cdot \mathrm{c}_{\mathrm{eq}}^{\mathrm{n}}}
$$

Dubinin-Radushkevich model

$$
\mathrm{q}_{\mathrm{eq}}=\mathrm{Q}_{\mathrm{m}} \cdot \exp \left(-\beta_{\mathrm{DR}} \cdot \varepsilon^{2}\right)
$$




$$
\begin{gathered}
\varepsilon=\mathrm{RT} \cdot \ln \left(1+\frac{1}{\mathrm{c}_{\mathrm{eq}}}\right) \\
\mathrm{E}_{\mathrm{ads}, \mathrm{DR}}=\frac{1}{\sqrt{2 \cdot \beta_{\mathrm{DR}}}}
\end{gathered}
$$

$\mathrm{K}_{\mathrm{L}}$ and $\mathrm{K}_{\mathrm{S}}$ thereby represent the model equilibrium constants, $\mathrm{Q}_{\mathrm{m}}$ represents the maximum adsorption capacity, $n$ represents the Sips model exponent, $\beta_{\mathrm{DR}}$ represents the activity coefficient that is related via Equation (8) to the mean free energy of adsorption, and $\mathrm{E}_{\mathrm{ads}, \mathrm{DR}}$ and $\varepsilon$ correspond to the Polanyi potential $[56,57]$.

\section{Results and Discussion}

Starch is a biopolymer that can be obtained from different plants such as root tuber (e.g., potato), corn (e.g., maize (corn) and wheat), and pea. Depending on their origin, the starches can feature different properties and thus diverse adsorption characteristics. Here, we studied the four diverse native starches from potato, corn, waxy corn, and wheat, as well as two oxidized starches from potato and corn (i.e., oxidized potato starch and oxidized corn starch). In particular, we investigated the surface properties utilizing charge density and streaming potential vs. $\mathrm{pH}$ curves, supported by the analysis of the chemical composition of the samples via elemental analysis, ATR-FTIR spectroscopy, and thermogravimetric analysis. The morphology of the starch samples was studied using SEM imaging as well as laser diffractometry in dry and wet states, respectively.

For simplification, the native starches are abbreviated with "n." and the oxidized starches with "o." in figures.

\subsection{Characterisation of Starch}

The streaming potential and the charge density were measured as a function of $\mathrm{pH}$ to determine the functional groups, which can be active for the adsorption process in water treatment applications (see Figure 1). According to the streaming potential vs. pH curves, native corn, waxy corn, and wheat starch were positively charged at $\mathrm{pH} 3$ and showed an isoelectric point (IEP) at $\mathrm{pH} 4.5,4.2$, and 5.0, respectively. The oxidized corn and potato starch had no IEP exhibiting a negative charge throughout the $\mathrm{pH}$ range of 3 to 9 , owing to the increased number of carboxyl and hydroxyl groups on the oxidized starch. At the $\mathrm{pH}$ of 5 , the oxidized starch samples exhibited a significant negative charge density of -8.51 and $-27.69 \mu \mathrm{eq} / \mathrm{g}$ for potato and corn starch, respectively (see Figure $1 \mathrm{~b}$ ), whereas the native starches only showed a charge density between -0.29 and $-0.28 \mu \mathrm{eq} / \mathrm{g}$. At $\mathrm{pH}$ values of 9 , all starch samples featured a negative charge, whereby the oxidized corn starch and the oxidized potato starch in particular showed the highest negative charge densities.

From the relatively high negative charge density of the oxidized corn starch $(-14.24 \mu \mathrm{eq} / \mathrm{g}$ at $\mathrm{pH}=3$ ), we were able to deduce that this sample exhibited more carboxyl groups than the other samples, as carboxyl groups have the lowest $\mathrm{pK}_{\mathrm{a}}$ relative to primary and secondary hydroxyl groups. At pH 5 and 9, the high charge densities indicated a higher number of hydroxyl groups than, e.g., oxidized potato starch, as hydroxyl groups are deprotonated in very high $\mathrm{pH}$ ranges. The relatively low difference in the charge density of oxidized potato starch between $\mathrm{pH}=5$ and $\mathrm{pH}=9$ indicated a relatively lower amount of hydroxyl functions in comparison to oxidized corn starch.

To further determine the chemical composition of the starch samples, we performed elemental analysis (Table 1), ATR-FTIR spectroscopy (Figure 2 and Figure S2, Table S1), and ${ }^{1} \mathrm{H}-\mathrm{NMR}$ analysis (Figure 3 and Figure S1, Table 2). From elemental analysis, it is noticeable that no nitrogen was present in the starches, indicating the complete absence of proteins. Besides the measured elements $\mathrm{C}, \mathrm{H}$, and $\mathrm{N}$, the starch structure contained a high amount of oxygen as well (see residual Table 2). Furthermore, all starch samples contained moisture, as shown in the moisture analysis in Figure S3. 

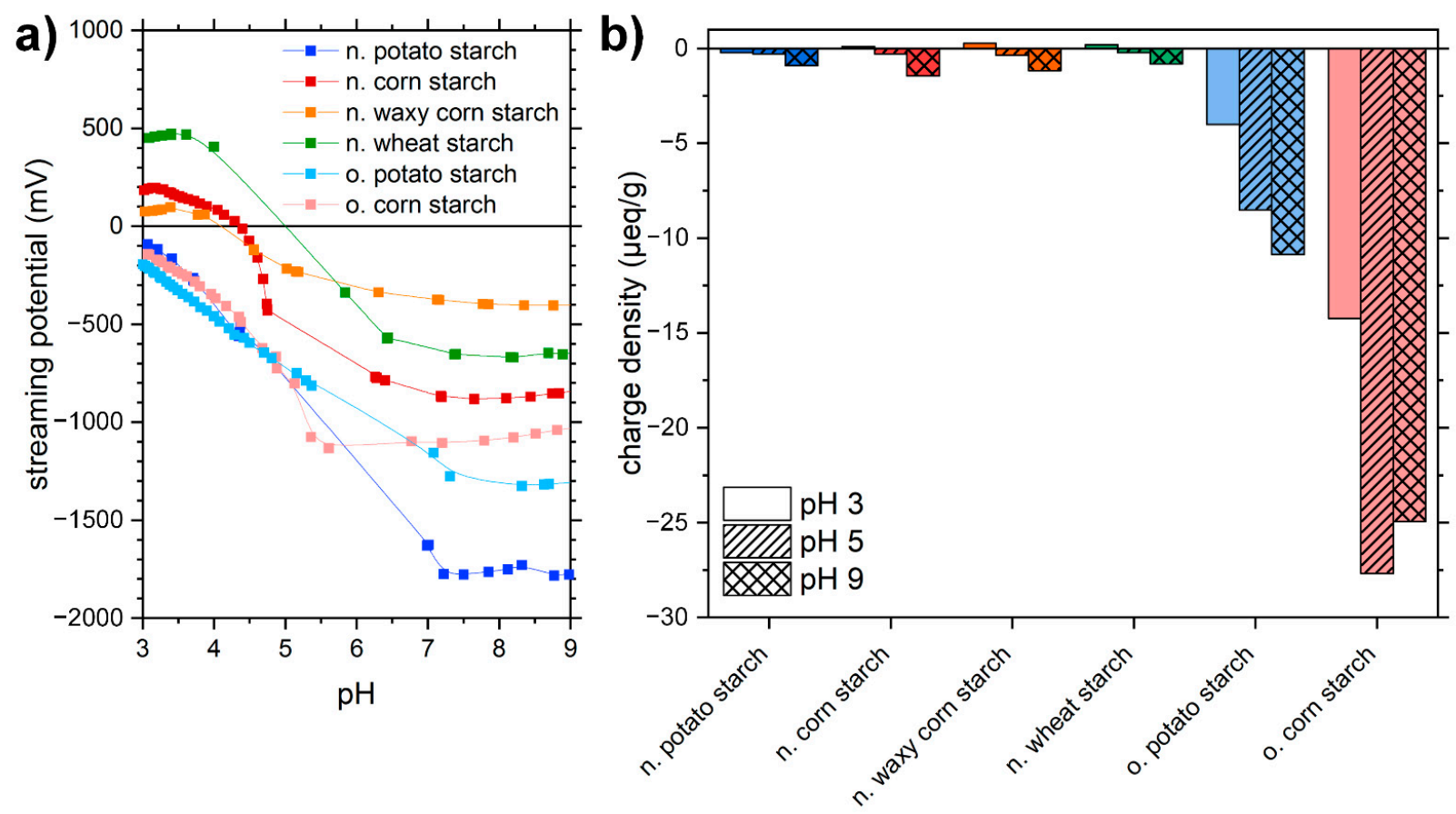

Figure 1. (a) Streaming potential vs. $\mathrm{pH}$ curves and (b) charge densities at $\mathrm{pH}$ values of 3 (solid), 5 (striped), and 9 (crossed) of native potato starch (blue), native corn starch (red), native waxy corn starch (orange), native wheat starch (green), oxidized potato starch (light blue), and oxidized corn starch (pink).

Table 1. Results of the elemental analysis for the different starches. Residue here describes the relative mass that was not attributed to the elements $\mathrm{C}, \mathrm{H}$, and $\mathrm{N}$.

\begin{tabular}{ccccc}
\hline Sample & C (wt \%) & H (wt \%) & N (wt \%) & Residue (wt \%) \\
\hline Native potato starch & 37.7 & 6.0 & 0 & 56.3 \\
Native corn starch & 39.8 & 6.3 & 0 & 54.0 \\
Native waxy corn starch & 39.6 & 6.1 & 0 & 54.3 \\
Native wheat starch & 39.7 & 6.3 & 0 & 54.1 \\
Oxidized potato starch & 39.3 & 6.2 & 0 & 54.6 \\
Oxidized corn starch & 37.4 & 5.8 & 0 & 56.9 \\
\hline
\end{tabular}

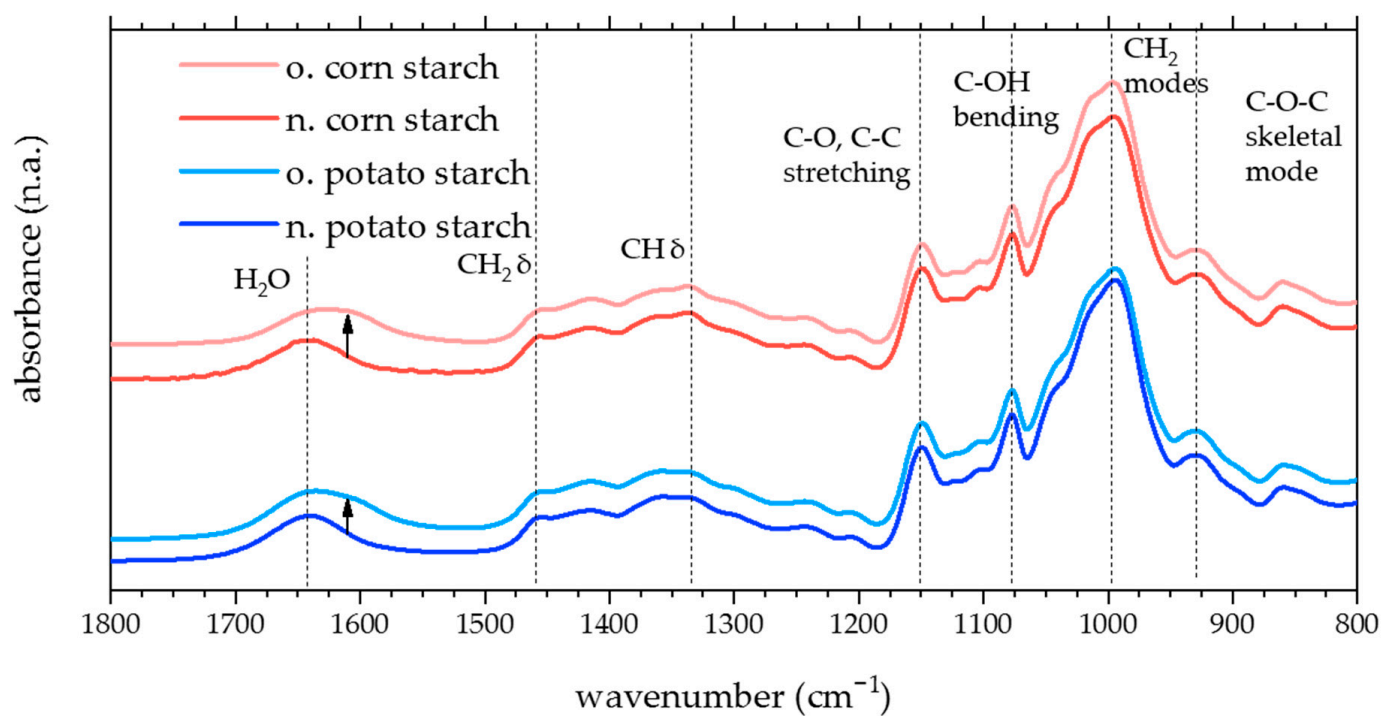

Figure 2. ATR-FTIR spectra comparison of oxidized and native corn as well as potato starches, $\mathrm{C}=\mathrm{O}$ vibration mode is marked as arrow and other vibrations are marked as dashed line. 


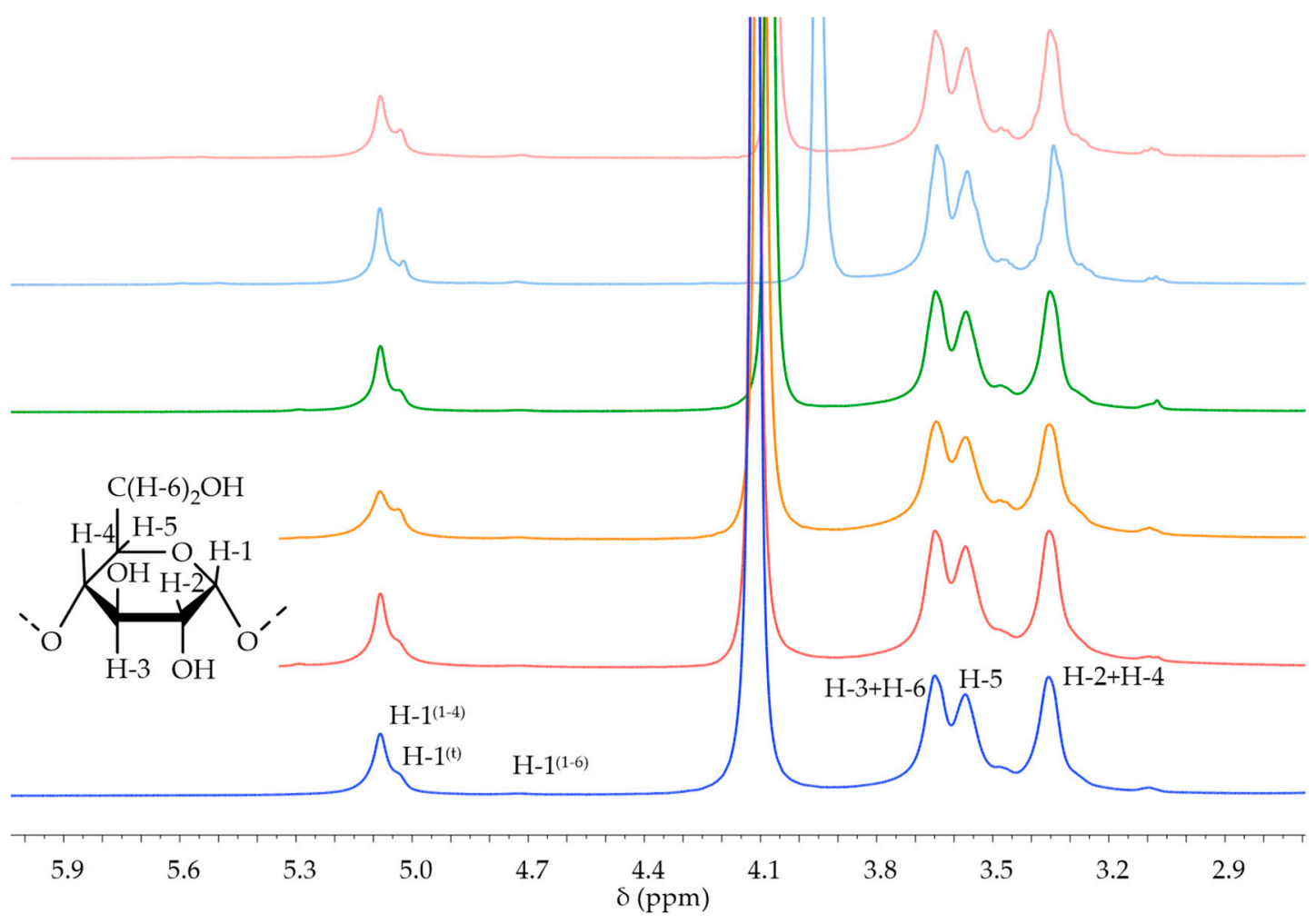

Figure 3. ${ }^{1} \mathrm{H}-\mathrm{NMR}$ of the starch samples in DMSO-d6 and $\mathrm{D}_{2} \mathrm{O}$ at $500 \mathrm{MHz}$ and $25{ }^{\circ} \mathrm{C}$ with assignments: $\mathrm{H}-1$ either from $\alpha-1,4\left(\mathrm{H}-1^{(1-4)}\right),-1,6\left(\mathrm{H}-1^{(1-6)}\right)$ glycosidic linkage or terminal unit $\left(\mathrm{H}-1^{(\mathrm{t})}\right), \mathrm{H}-2-\mathrm{H}-5$ hydrogens along glucose ring, and $\mathrm{H}-6$ for $\mathrm{CH}_{2} \mathrm{OH}$. Native potato starch shown in blue, native corn starch in red, native waxy corn starch in orange, native wheat starch in green, oxidized potato starch in light blue, and oxidized corn starch in pink. Respective signals between 4.2 and 3.9 ppm corresponded to $\mathrm{H}_{2} \mathrm{O}$ and signals at $2.5 \mathrm{ppm}$ to DMSO.

Table 2. Calculated degree of branching (BD) (see Equation (1)) for the different starch samples and the values for the respective integrals used for calculation. The respective spectra are shown in Figure S1.

\begin{tabular}{|c|c|c|c|}
\hline Starch & $\begin{array}{c}\text { Integral H1 } \alpha-1,4+\mathrm{H}-1(\mathrm{t}) \\
5.40 \mathrm{ppm}-4.90 \mathrm{ppm}\end{array}$ & $\begin{array}{l}\text { Integral H-1 } \alpha-1,6 \\
4.80 \mathrm{ppm}-4.65 \mathrm{ppm}\end{array}$ & BD \\
\hline Native potato & 1.0000 & 0.0414 & $4.0 \%$ \\
\hline Native corn & 1.0000 & 0.0428 & $4.1 \%$ \\
\hline Native waxy corn & 1.0000 & 0.0564 & $5.3 \%$ \\
\hline Native wheat & 1.0000 & 0.0567 & $5.4 \%$ \\
\hline Oxidized potato & 1.0000 & 0.0578 & $5.5 \%$ \\
\hline Oxidized corn & 1.0000 & 0.0333 & $3.2 \%$ \\
\hline
\end{tabular}

The FTIR spectra of all six samples are almost congruent, all exhibiting vibration modes consistent with the literature (Figure S2). A detailed annotation is given in Table S1 [58-60]. All starches exhibited minor deviations in the intensity of the $\mathrm{OH}$-related peak at $3000-3680 \mathrm{~cm}^{-1}$ (see Figure S2) and the peak at $1643 \mathrm{~cm}^{-1}$ due to varying amounts of residual water [60]. Furthermore, the variation of the peak at $930 \mathrm{~cm}^{-1}$ related to the $\alpha-1,4$ glycosidic bond indicated different branching degrees, since peaks of $\alpha-1,6$ glycosidic linkages are typically shifted toward higher wavenumbers [60]. Due to the overlap of the peaks, an accurate quantification of the branching degree was not possible via ATR-FTIR. The oxidized starches showed similar variations in the before mentioned peaks. Additionally, a peak at $1614 \mathrm{~cm}^{-1}$ was visible, which was attributed to the valence $\mathrm{C}=\mathrm{O}$ mode (Figure 2, marked by an arrow). In consistency with the negative streaming potentials of the starches at low $\mathrm{pH}$ values, this indicated the formation of $\mathrm{COOH}$ functionalities during the oxidation process. 
The complementary bands of the $\mathrm{COOH}$ functionality were bound to overlap with the existing $\mathrm{OH}$ bands.

Similar to the FTIR data, the ${ }^{1} \mathrm{H}-\mathrm{NMR}$ spectra of the different starches were mainly congruent (Figure 3). Therefore, the peak assignment was valid for all starches. Following standard numeration procedure, we found that the $\mathrm{H}-1$ hydrogen was coupled to the carbon participating in the $\alpha-1,4$ (1-4) or $\alpha-1,6$ (1-6) glycosidic linkage. The peaks of H-1 linked to a linear $\alpha-1,4$ linkage and of $\mathrm{H}-1$ of terminal (t) glucose units were positioned at 5.08 and $5.04 \mathrm{ppm}$, respectively [52]. The peak corresponding to the H-1 $\alpha-1,6$ glycosidic linkage was slightly shifted to lower values to $4.74 \mathrm{ppm}$. The other ring hydrogen atoms were numbered along the C-chain. The complementary peaks were found at $3.65 \mathrm{ppm}$ $(\mathrm{H}-3+\mathrm{H}-6), 3.57 \mathrm{ppm}(\mathrm{H}-5)$, and $3.36 \mathrm{ppm}(\mathrm{H}-2+\mathrm{H}-4)$ [52]. Since they included the linear, branched, and terminal unit signals, they were comparatively broad.

To determine the branching degree (BD), we used the more separated peaks of $\mathrm{H}-1$ $\alpha-1,4+\mathrm{H}-1(\mathrm{t})$ and $\mathrm{H}-1 \alpha-1,6$ (Equation (1), compare Figure S1). The calculated BD $\%$ are listed in Table 2.

Apparently, the oxidized corn starch had a lower BG than the native corn starch, whilst oxidized potato starch and native potato starch showed an opposite relation. For starch being a biopolymer, deviations in the branching degree can be possible depending on the synthesizing plant and natural circumstances of synthesis. Another possible explanation for the differences of native and oxidized corn starch could be that the oxidization reduced the branching degree by breaking the $\alpha-1,6$-linkage as amylopectin is more prone to oxidization than amylose [61,62].

The thermogravimetric analysis of the samples under air and nitrogen atmosphere (Figure 4) featured typical behavior for starch samples, as seen in comparable studies [63,64]. In general, the weight loss of starch samples can be attributed to three different stages. Up to $150{ }^{\circ} \mathrm{C}$ physical dehydration of adsorbed water can be seen. Around $300{ }^{\circ} \mathrm{C}$, chemical dehydration begins, and above $500{ }^{\circ} \mathrm{C}$, carbonization reactions with transition first to aromatic structures and later to amorphous carbon takes place $[63,64]$. Under air atmosphere, further degradation to $\mathrm{CO}_{2}$ and $\mathrm{H}_{2} \mathrm{O}$ occurs. As stated in the literature, thermal decomposition is not affected by the initial water content or crystallinity but by the overall branching degree as amylopectin is retarding decomposition [63,65]. Moreover, functionalization facilitates the thermal degradation around $300{ }^{\circ} \mathrm{C}[66]$.
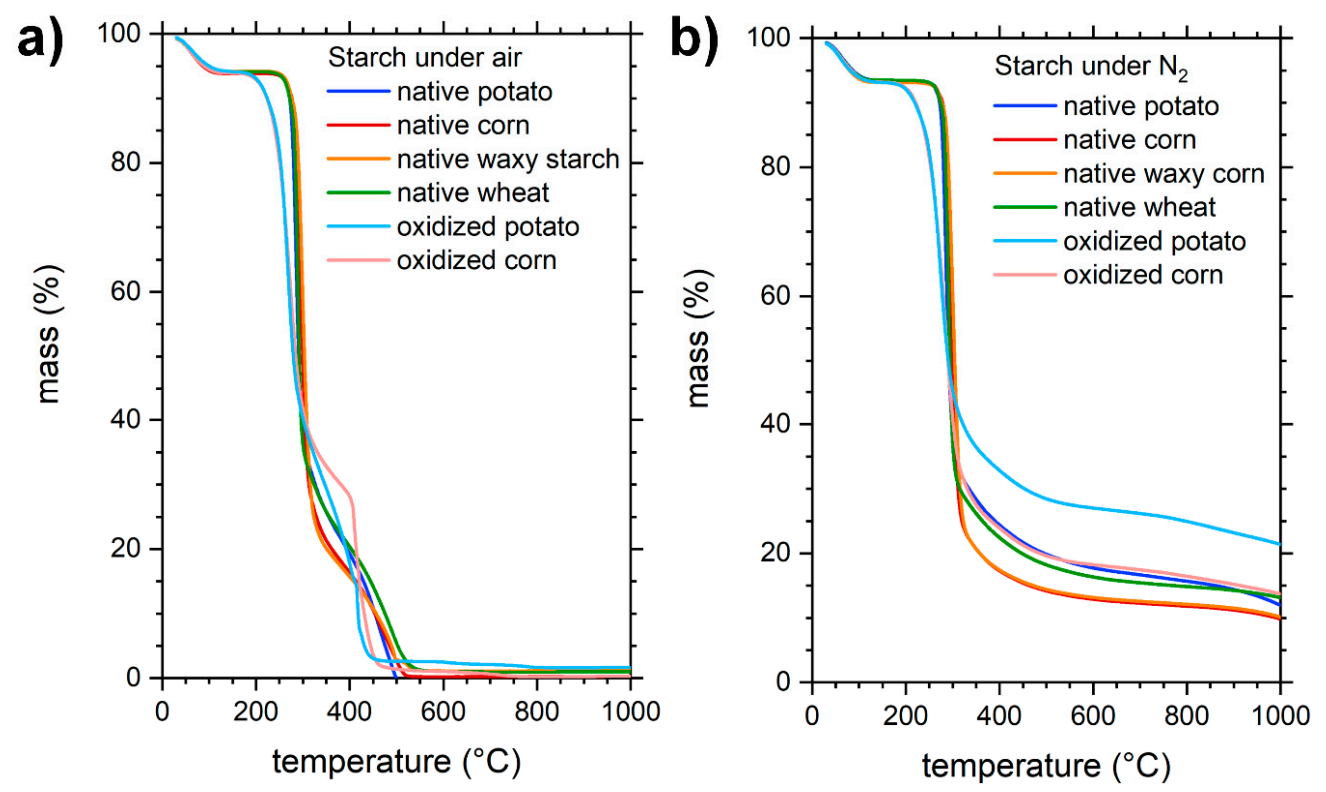

Figure 4. Thermogravimetric analysis (a) under air and (b) under nitrogen atmosphere of native potato starch (blue), native corn starch (red), native waxy corn starch (orange), native wheat starch (green), oxidized potato starch (light blue), and oxidized corn starch (pink). 
In general, it is visible that both, under air and nitrogen atmosphere, oxidized starches showed a lower stability in the temperature range between $200^{\circ} \mathrm{C}$ and $300^{\circ} \mathrm{C}$. This can be attributed to the introduced oxygen functionalities that facilitate the combustion of the starch structure into $\mathrm{CO}_{2}$ and $\mathrm{H}_{2} \mathrm{O}$. All samples decomposed completely under air atmosphere at $1000{ }^{\circ} \mathrm{C}$ (residuals were between 0 and $2 \mathrm{wt} \%$, which is within the limit of detection). Thus, all samples were purely organic without appreciable amounts of inorganic impurities. Under nitrogen, the starch samples exhibited a final residuum of around 10 to $14 \mathrm{wt} \%$, except for the oxidized potato starch with $21 \mathrm{wt} \%$. This higher residual weight is attributed to an increased formation of amorphous carbon structures, which indicates that with the modification process of the oxidized starch, a significant amount of the carbohydrate ring structure has been opened and reacted to aldehyde functionalities. These enhance the thermal transition to aromatic furan derivatives and therefore increased thermal stability above $500{ }^{\circ} \mathrm{C}$ [63]. This is in agreement with the results deduced from charge density measurement. We assume that oxidized potato starch exhibited a higher number of aldehyde groups instead of carboxyl or hydroxyl groups, thus not contributing significantly to the negative charge density and differences of the charge density over $\mathrm{pH}$. In contrast, oxidized corn starch exhibited more carboxylic functionalities that facilitate thermal degradation under $\mathrm{N}_{2}$.

Potential minor inorganic impurities of the starch samples were analyzed by SEM-EDX (see Figures S5-S10b). The chemical mapping of the samples can be seen in Figures S5-S10a in the Supplementary Information. From this investigation, we were able to deduce that all starch samples contained low amounts of impurities, such as $\mathrm{Na}, \mathrm{Fe}, \mathrm{Si}, \mathrm{P}, \mathrm{S}, \mathrm{Cl}, \mathrm{K}, \mathrm{Ca}$, and F, whereby most of these elements were not homogeneously distributed over the sample (see Figures S5-S10b). Additionally, in the EDX analysis, the starch was digested by $\mathrm{HNO}_{3}$ and $\mathrm{H}_{2} \mathrm{O}_{2}$ under microwave irradiation with a subsequent analysis by ICP-OES for the common elements $\mathrm{Na}, \mathrm{K}, \mathrm{Ca}, \mathrm{Si}, \mathrm{P}$, and $\mathrm{S}$. The results are depicted in Table 3. It is noticeable that the starch samples contained different inorganic elements with total amounts between 2.5 and $11.3 \mathrm{mg} / \mathrm{g}$.

Table 3. Relative weight of contained elements analyzed by ICP-OES after liquid digestion of the starch samples by $\mathrm{HNO}_{3}$ and $\mathrm{H}_{2} \mathrm{O}_{2}$ with microwave irradiation.

\begin{tabular}{|c|c|c|c|c|c|c|c|}
\hline Sample & $\begin{array}{c}S \\
(\mathrm{mg} / \mathrm{g})\end{array}$ & $\begin{array}{c}P \\
(\mathrm{mg} / \mathrm{g})\end{array}$ & $\begin{array}{c}\mathrm{Si} \\
(\mathrm{mg} / \mathrm{g})\end{array}$ & $\begin{array}{c}\mathrm{Na} \\
(\mathrm{mg} / \mathrm{g})\end{array}$ & $\begin{array}{c}\mathrm{K} \\
(\mathrm{mg} / \mathrm{g})\end{array}$ & $\begin{array}{c}\mathrm{Ca} \\
(\mathrm{mg} / \mathrm{g})\end{array}$ & $\underset{(\mathrm{mg} / \mathrm{g})}{\text { Sum }}$ \\
\hline Native potato starch & 0.6 & 0.7 & 2.4 & 2.0 & 2.7 & 0.3 & 8.8 \\
\hline Native corn starch & 0.4 & 0.1 & 0.6 & 1.2 & 0.8 & 0.1 & 3.3 \\
\hline Native waxy corn starch & 0.3 & 0.1 & 0.3 & 1.1 & 0.6 & 0.1 & 2.5 \\
\hline Native wheat starch & 0.2 & 0.5 & 0.2 & 0.9 & 0.5 & 0.1 & 2.3 \\
\hline Oxidized potato starch & $0.1 *$ & 0.8 & 0.2 & 9.4 & 0.7 & 0.1 & 11.3 \\
\hline Oxidized corn starch & 0.1 & 0.1 & 0.1 & 6.1 & 0.3 & 0.2 & 7.1 \\
\hline
\end{tabular}

* value below detection limit.

Furthermore, the starch samples were also analyzed for their potential micro- or mesoporous structure with nitrogen and carbon dioxide sorption measurements (see Figure S11). As expected, none of the starch samples showed a significant specific surface area or detectable micro- or mesopore structure in dry state.

To investigate the morphology and macroscopic surface properties, we examined the six starch samples using scanning electron microscopy (SEM) (Figure 5). A corresponding particle size distribution in dry state is plotted in Figure S4 in the Supplementary Information. Native corn starch, native waxy corn starch, and the oxidized corn starch featured a more polyhedral shape, while the native potato starch, native wheat starch, and oxidized potato starch exhibited more spherical and oval shapes. 

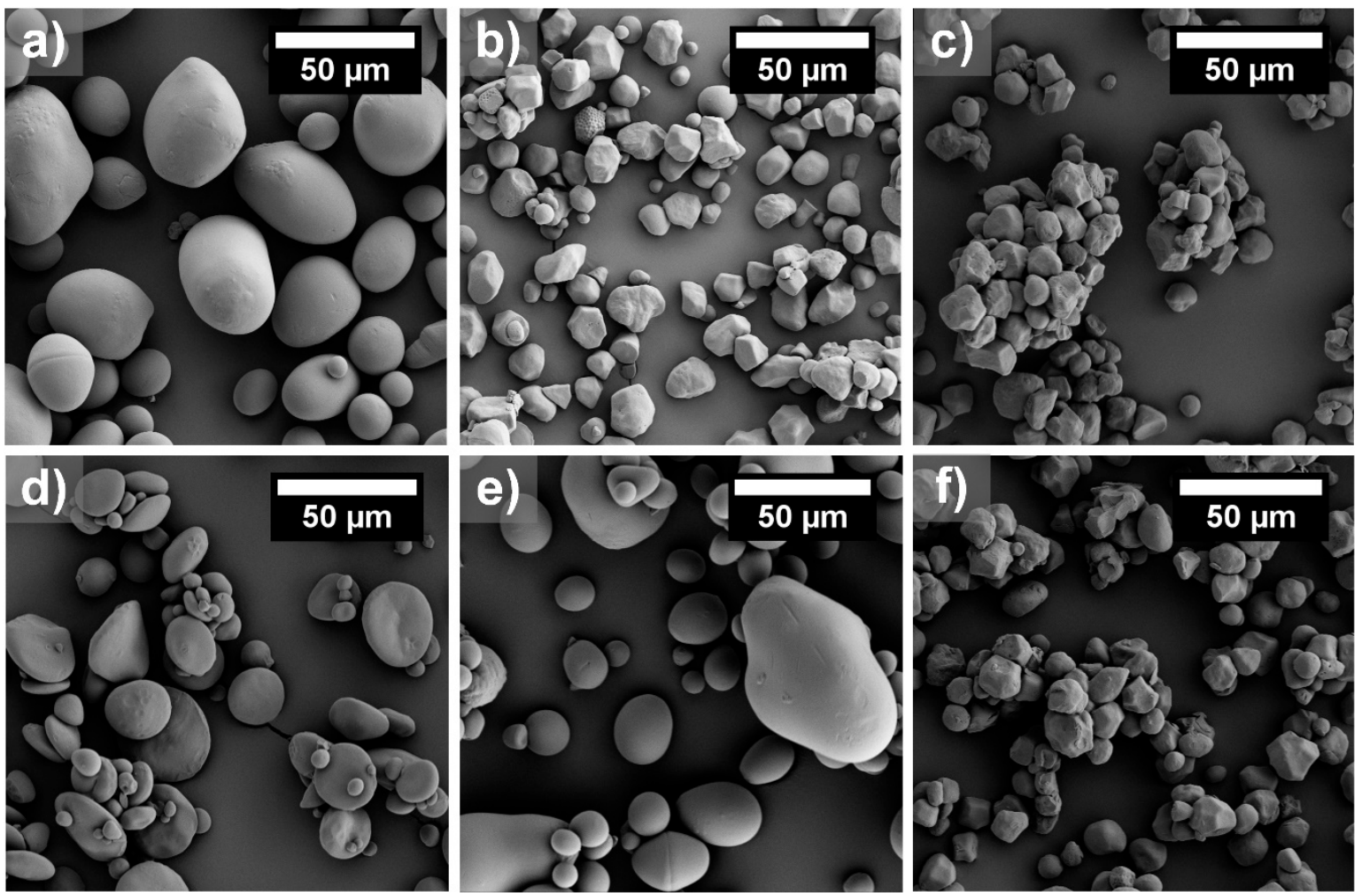

Figure 5. SEM images of (a) native potato starch, (b) native corn starch, (c) native waxy corn starch, (d) native wheat starch, (e) oxidized potato starch, and (f) oxidized corn starch.

The particle size distribution of the six starch samples as a function of time in ultrapure water was measured by laser diffractometry (see Figure 6). The bimodal progression of the particle size distribution curves indicated the existence of two types of particle sizes: small particles with a diameter between 0.1 and $5 \mu \mathrm{m}$ and larger ones between 30 and $100 \mu \mathrm{m}$. Native corn starch and native wheat starch featured very sharp peaks at around $17 \mu \mathrm{m}$ and $22 \mu \mathrm{m}$, respectively. The particle size did not change after $24 \mathrm{~h}$. Native waxy corn starch also possessed a very sharp peak at $11 \mu \mathrm{m}$, whereby after $24 \mathrm{~h}$, an increase in particle size to $17 \mu \mathrm{m}$ was visible. Native potato starch and oxidized potato starch exhibited both a peak at $48 \mu \mathrm{m}$. After $24 \mathrm{~h}$, an increase in particle size caused by swelling was not observed. In contrast, oxidized corn starch possessed a much broader particle size distribution at around $65 \mu \mathrm{m}$ with a decrease in particle size after $24 \mathrm{~h}$ to $19 \mu \mathrm{m}$. Furthermore, the second peak at around 0.1 to $3 \mu \mathrm{m}$ decreased significantly, yielding in particles with diameters around $0.3 \mu \mathrm{m}$ after $24 \mathrm{~h}$. As shown in the SEM images of the dry samples, the largest particles were observed for $n$. and o. potato starch, which was in agreement with the particle size distribution curves measured by laser diffractometry. However, the particle sizes measured by laser diffractometry at 0 min for $n$. waxy corn starch and o. corn starch were relatively large, as well in comparison to the relatively small particles depicted in the SEM images. As shown in the SEM images, the small particles were aggregated to larger ones, yielding in larger particles in the particle size distribution curves. After $24 \mathrm{~h}$ stirring in water, the particles sizes were smaller because the particle aggregates were dispersed by stirring featuring the particle sizes of the single particles in solution. The dispersed starch particles in water after $24 \mathrm{~h}$ of constant stirring are shown in Figure 7.

\subsection{Low-Concentration Sorption Experiments}

Adsorption experiments with the ions of $\mathrm{Al}^{3+}, \mathrm{Cd}^{2+}$, and $\mathrm{Pb}^{2+}$ were conducted with all six starch samples in order to evaluate the potential application of starch for wastewater treatment. To reconstruct pollutions in a concentration range of potential real contaminants, 
we tested concentrations of 0.1 and $1 \mathrm{mg} / \mathrm{L}$ of the respective metal ions from the sulfate salt in screening experiments with $\mathrm{Al}^{3+}, \mathrm{Pb}^{2+}$, and $\mathrm{Cd}^{2+}$ (Figure 8). Native potato starch, oxidized potato starch, and oxidized corn starch in particular possessed high adsorption rates with over $80 \%$ for $\mathrm{Al}^{3+}, \mathrm{Cd}^{2+}$, and $\mathrm{Pb}^{2+}$ for 0.1 and $1 \mathrm{mg} / \mathrm{L}$. For $0.1 \mathrm{mg} / \mathrm{L} \mathrm{Al}^{3+}$, native potato starch and oxidized corn starch featured an excellent adsorption rate of $100 \%$. Furthermore, oxidized corn starch achieved a perfect separation of $100 \%$ for $0.1 \mathrm{mg} / \mathrm{L}$ $\mathrm{Cd}^{2+}$, yielding drinking water quality values below $0.003 \mathrm{mg} / \mathrm{L}$ for $\mathrm{Cd}^{2+}$ (related to the limit specified by the WHO) [67]. Hence, both oxidized starches adsorbed around $99 \%$ of $\mathrm{Cd}^{2+}$ at $1 \mathrm{mg} / \mathrm{L}$. For $\mathrm{Pb}^{2+}$, a complete removal was not observed, but it is noticeable that the adsorption rate of the native potato and wheat starch as well as for both oxidized starches increased insignificantly with increasing initial concentration from 0.1 to $1 \mathrm{mg} / \mathrm{L}$. The excellent adsorption properties of native potato starch and both oxidized starches for $\mathrm{Al}^{3+}, \mathrm{Cd}^{2+}$, and $\mathrm{Pb}^{2+}$ were in agreement with the zetapotential measurements, featuring a higher charge density in comparison to the other native starch samples (see Figure 1b).
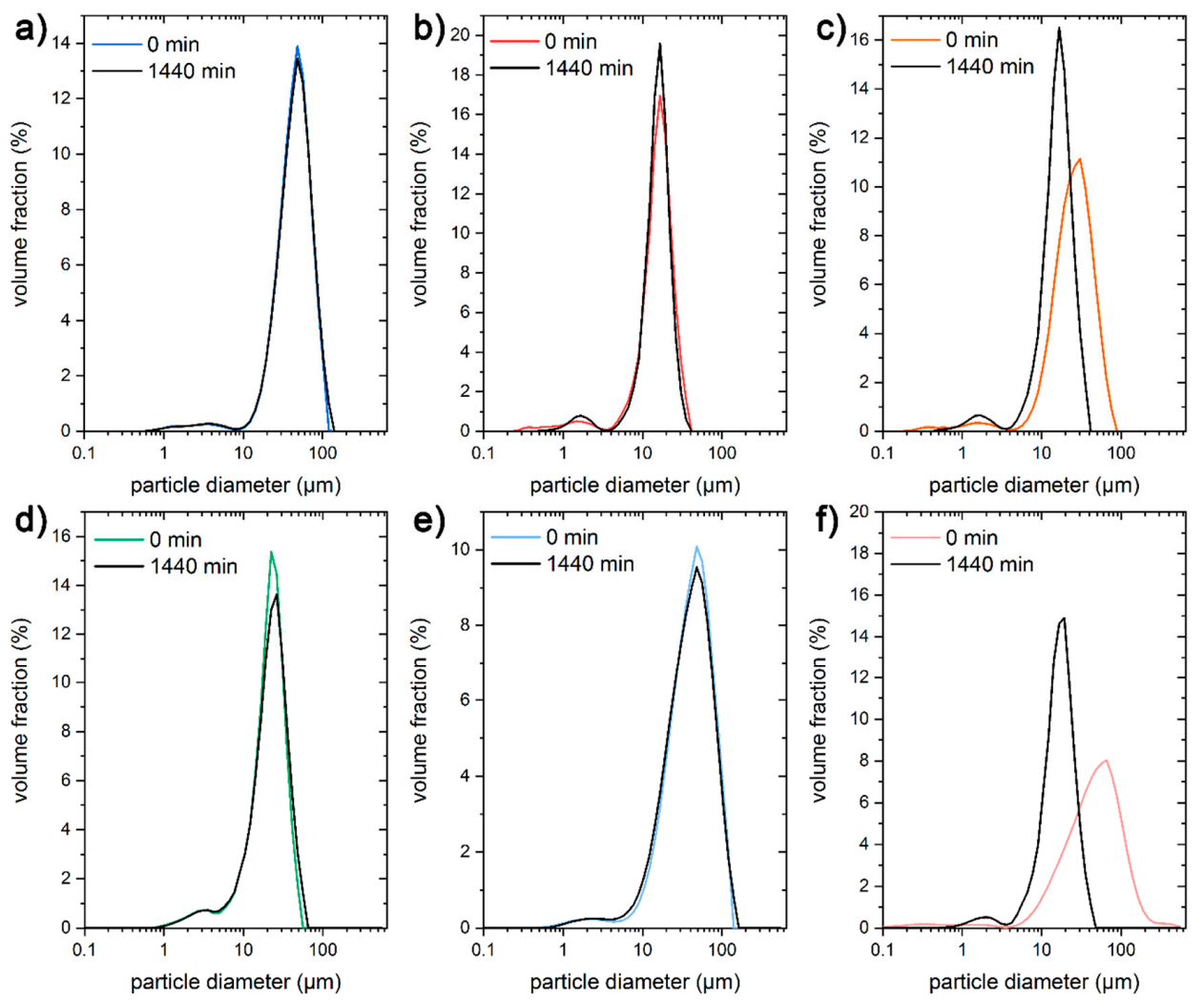

Figure 6. Particle size distributions in aqueous solution at $0 \mathrm{~min}$ and $24 \mathrm{~h}$ of (a) native potato starch, (b) native corn starch, (c) native waxy corn starch, (d) native wheat starch, (e) oxidized potato starch, and (f) oxidized corn starch.

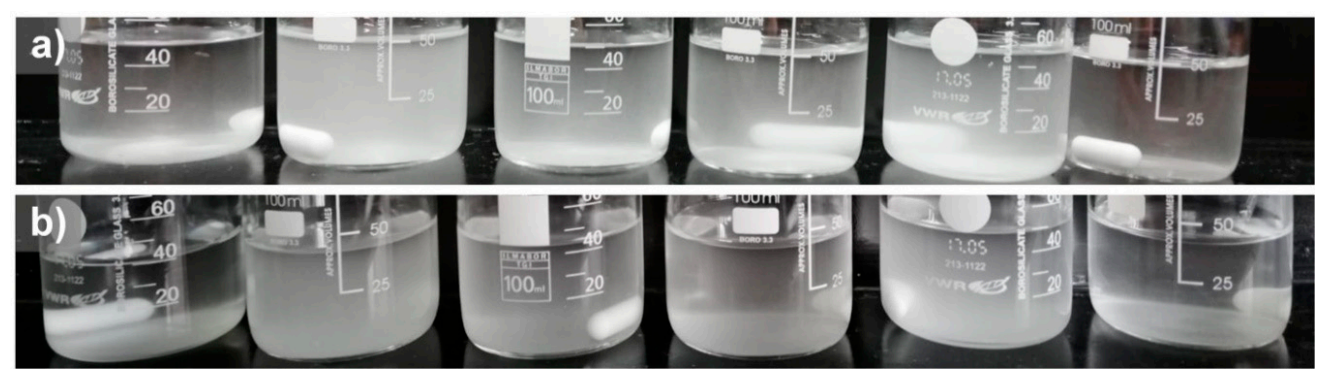

Figure 7. Solubility experiments of starch (a) directly after addition of starch and (b) after stirring for 24 h. From left to right: Native potato starch, native corn starch, native waxy corn starch, native wheat starch, oxidized potato starch, and oxidized corn starch. 
a)

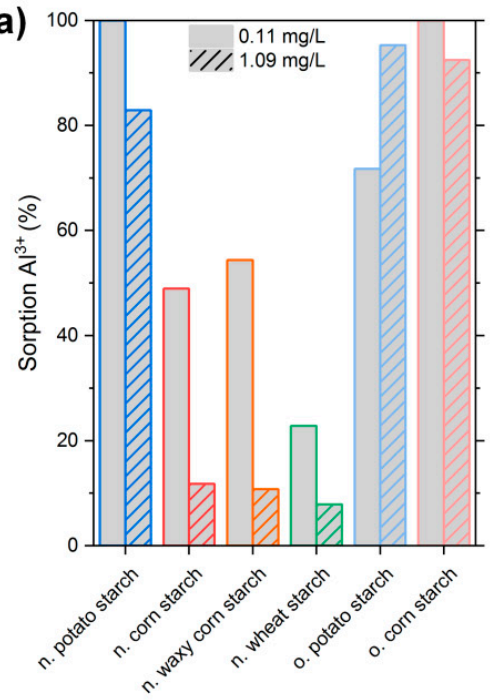

b)

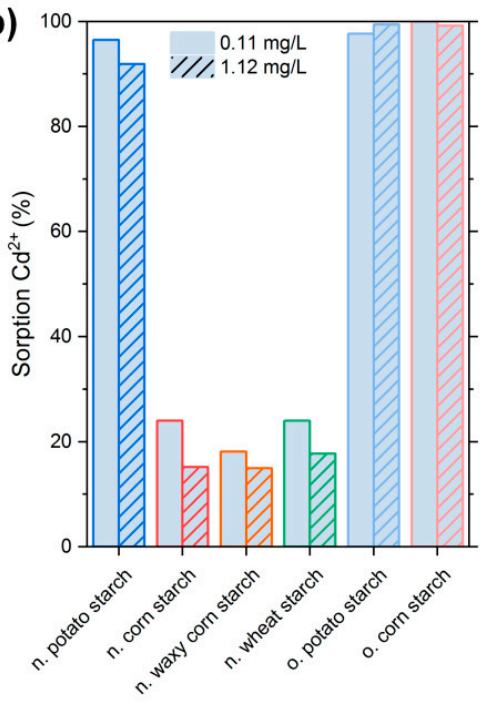

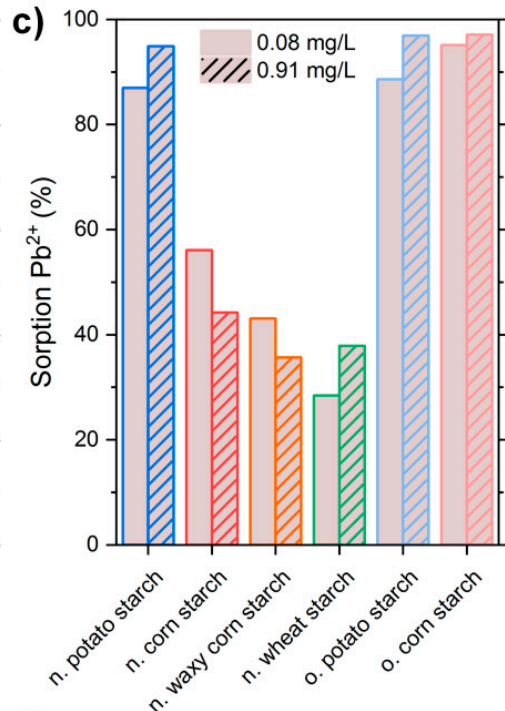

Figure 8. Screening experiments with $\mathrm{Al}^{3+}, \mathrm{Pb}^{2+}$, and $\mathrm{Cd}^{2+}$ with the percentage sorption of (a) aluminum from $\mathrm{Al}_{2}\left(\mathrm{SO}_{4}\right)_{3}$ adsorption experiments with an initial concentration of aluminum ions of $0.11 \mathrm{mg} / \mathrm{L}$ (solid) and $1.09 \mathrm{mg} / \mathrm{L}$ (striped); (b) cadmium from $\mathrm{CdSO}_{4}$ adsorption experiments with an initial concentration of cadmium ions of $0.11 \mathrm{mg} / \mathrm{L}$ (solid) and $1.12 \mathrm{mg} / \mathrm{L}$ (striped); (c) lead from $\mathrm{PbSO}_{4}$ adsorption experiments with an initial concentration of lead ions of $0.08 \mathrm{mg} / \mathrm{L}$ (solid) and $0.91 \mathrm{mg} / \mathrm{L}$ (striped) on native potato starch (blue), native corn starch (red), native waxy corn starch (orange), native wheat starch (green), oxidized potato starch (light blue), and oxidized corn starch (pink). The corresponding $\mathrm{pH}$ values for the sorption experiments are shown in Figures S12-S14. The corresponding adsorption of sulfate ions is shown in Figure S15, whereby most of the S-concentrations were below the limit of detection for S.

For the adsorption of $\mathrm{SO}_{4}{ }^{2-}$ ions, the highest percentage separation with around $76 \%$ was achieved with native potato starch for the $\mathrm{CdSO}_{4}$ solution with a concentration of $0.1 \mathrm{mg} / \mathrm{L} \mathrm{Cd}^{2+}$ (see Figure S15). For starch being negatively charged in the $\mathrm{pH}$ range of the respective experiments, the adsorption of negatively charged sulfate species is unusual, and therefore some kind of cooperative mechanism for the adsorption together with the corresponding metal ion could be possible.

\subsection{Sorption Isotherm Experiments with $\mathrm{Al}^{3+}, \mathrm{Pb}^{2+}$, and $\mathrm{Cd}^{2+}$}

To investigate the adsorption behavior in more detail, we selected the oxidized and native potato and corn starches to analyze the adsorption isotherms for $\mathrm{Al}_{2}\left(\mathrm{SO}_{4}\right)_{3(\mathrm{aq})}$, $\mathrm{CdSO}_{4(\mathrm{aq})}$, and $\mathrm{PbSO}_{4(\mathrm{aq})}$. The obtained adsorption isotherms were fitted with the respective adsorption isotherm models to obtain insights into the adsorption process. The decision to the respective models was made upon the coefficient of determination (COD) $R^{2}$. The corresponding equations to the models used can be seen in Section 2.4, and a comparison of different fits is shown in Figures S22-S25.

In Figure 9, the adsorption isotherms for $\mathrm{Al}_{2}\left(\mathrm{SO}_{4}\right)_{3}$ solutions are shown, featuring a very high adsorption rate for both oxidized starches for initial concentrations of $\mathrm{Al}^{3+}$ between 40 and $250 \mu \mathrm{mol} / \mathrm{L}$. The adsorption capacities of the oxidized starches were reached at 74 and $102 \mu \mathrm{mol} / \mathrm{g}$ for oxidized corn and potato starch, respectively. The native starches possessed distinct lower adsorption rates with a maximum experimental adsorption capacity of $10 \mu \mathrm{mol} / \mathrm{g}$ for native corn starch and $27 \mu \mathrm{mol} / \mathrm{g}$ for native potato starch. This trend is in agreement with the preliminary adsorption measurements for $1 \mathrm{mg} / \mathrm{L}$ and $0.1 \mathrm{mg} / \mathrm{L}$ (for comparison see Figure 8). In experiments with native potato starch and native corn starch, a constant adsorption of sulfate ions in the range of $20 \%$ to $40 \%$ for concentrations of above $200 \mu \mathrm{mol} / \mathrm{L} \mathrm{SO}_{4}{ }^{2-}$ can be seen, which is unusual for the also negatively charged starch (see Figure S16a). 

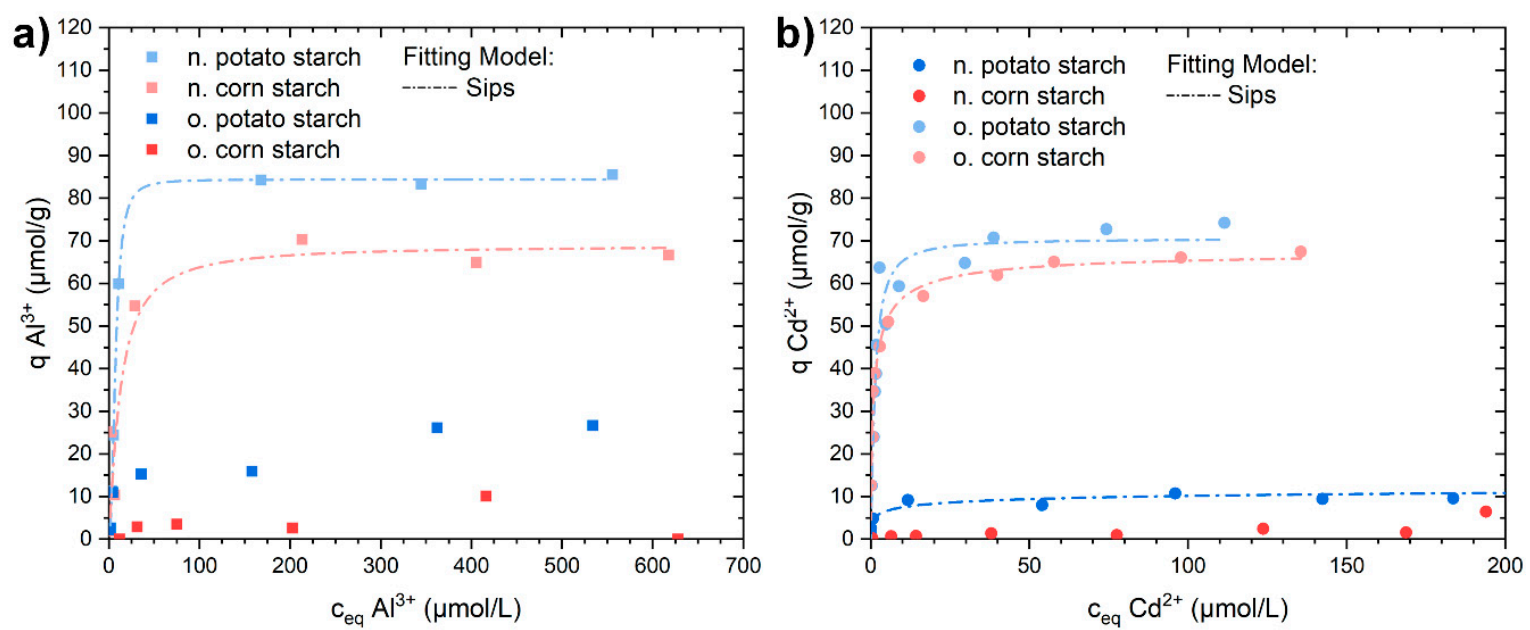

Figure 9. Adsorption capacity (a) for $\mathrm{Al}^{3+}$ from $\mathrm{Al}_{2}\left(\mathrm{SO}_{4}\right)_{3}$ solution and (b) for $\mathrm{Cd}^{2+}$ of $\mathrm{CdSO}_{4}$ solution and corresponding Sips isotherm model fits. Native potato starch is shown in blue, native corn starch in red, oxidized potato starch in light blue, and oxidized corn starch in pink. The corresponding $\mathrm{SO}_{4}{ }^{2-}$ adsorption and $\mathrm{pH}$ values can be seen in Figure $\mathrm{S} 22$ for the experiment with $\mathrm{Al}_{2}\left(\mathrm{SO}_{4}\right)_{3}$ solution and Figure $\mathrm{S} 23$ for the experiment with $\mathrm{CdSO}_{4}$ solution. Native potato starch did not exhibit a viable fitting for Sips model in the $\mathrm{Al}_{2}\left(\mathrm{SO}_{4}\right)_{3}$ sorption experiments. Native corn starch (red) did not exhibit a viable fitting for Sips model $\left(\mathrm{R}^{2}<0.7\right)$ for both isotherms.

As fitting functions, Langmuir, Sips, and Dubinin-Radushkevich were chosen, whereby the derived fitting parameters and coefficient of determination are stated in Table 4 . The fitting for the Sips isotherm with the best $\mathrm{R}^{2}$ is given in Figure 9, and the diagram with all three mentioned fits is depicted in Figure S22. Native corn starch exhibited no reasonable converging fit for any model applied due to the generally low adsorption values. Sips isotherm model was in greatest consistency with the data in terms of $R^{2}\left(R^{2}=0.999\right.$ for o. potato starch and $R^{2}=0.916$ for o. corn starch). This led to the assumption that the adsorption of $\mathrm{Al}^{3+}$ on starch cannot be described by a simple monolayer process onto a homogeneous surface. Sips isotherm model, as a combination of Freundlich and Langmuir, describes adsorption onto heterogeneous surfaces and second-order processes more efficiently $[54,57]$. Moreover, the Sips isotherm model exponent $\mathrm{n}$ indicates a heterogeneity of the adsorber surface for values above $1[57,68]$. The calculated maximum adsorption capacities from the Sips fittings were also in agreement with the highest experimental adsorption capacities.

Table 4. Fitting parameters for Langmuir, Sips, and Dubinin-Radushkevich isotherm models for adsorption from $\mathrm{Al}_{2}\left(\mathrm{SO}_{4}\right)_{3}$ solution. Here, $\mathrm{Q}_{\mathrm{m}}$ is the maximal sorption capacity, $\mathrm{K}$ is the equilibrium constant for the respective model, $\mathrm{n}$ is the Sips isotherm model exponent, and $\mathrm{E}_{\mathrm{ads}, \mathrm{DR}}$ is the mean free energy of adsorption derived from the Dubinin-Radushkevich model. No applied model gave a reasonable fit to the isotherm of native corn starch. Sips isotherm model gave no reasonable fit for native potato starch.

\begin{tabular}{|c|c|c|c|c|c|c|c|}
\hline Sample & Model & $\underset{\mu \mathrm{mol} / \mathrm{g}}{\mathrm{Q}_{\mathrm{m}}}$ & $\underset{\mathrm{L} / \mu \mathrm{mol}}{\mathrm{K}}$ & $\begin{array}{c}\beta_{\mathrm{DR}} \\
\mathrm{mol}^{2} / \mathrm{J}^{2}\end{array}$ & $\mathbf{n}$ & $\begin{array}{l}E_{\text {ads,DR }} \\
\mathrm{kJ} / \mathrm{mol}\end{array}$ & $\mathbf{R}^{2}(\mathrm{COD})$ \\
\hline \multirow{2}{*}{ Native potato starch } & Langmuir & $23.1 \pm 2.5$ & $0.12 \pm 0.08$ & - & - & - & 0.850 \\
\hline & Dubinin-Radushkevich & $21.0 \pm 2.5$ & - & $2.16 \cdot 10-6 \pm 1.50 \cdot 10-6$ & - & $0.48 \pm 0.17$ & 0.791 \\
\hline \multirow{3}{*}{ Oxidized potato starch } & Langmuir & $88.5 \pm 6.0$ & $0.09 \pm 0.02$ & - & - & - & 0.944 \\
\hline & Sips & $84.4 \pm 0.7$ & $0.01 \pm 0.00$ & - & $2.30 \pm 0.1$ & - & 0.999 \\
\hline & Dubinin-Radushkevich & $83.6 \pm 1.9$ & - & $5.91 \cdot 10-6 \pm 5.8 \cdot 10-7$ & - & $0.29 \pm 0.01$ & 0.993 \\
\hline \multirow{3}{*}{ Oxidized corn starch } & Langmuir & $70.5 \pm 6.0$ & $0.07 \pm 0.03$ & - & - & - & 0.913 \\
\hline & Sips & $68.9 \pm 7.2$ & $0.05 \pm 0.06$ & - & $1.2 \pm 0.5$ & - & 0.916 \\
\hline & Dubinin-Radushkevich & $66.1 \pm 6.1$ & - & $2.16 \cdot 10-5 \pm 1.50 \cdot 10-5$ & - & $0.48 \pm 0.17$ & 0.864 \\
\hline
\end{tabular}

The modeling with the Dubinin-Radushkevich isotherm showed values of $R^{2}$ close to the ones of the Sips model, giving the opportunity to compare among the different samples the derivable mean free energy of adsorption calculated with Equation (8). It is shown 
that the values for $E_{a d s}$ increased from native potato starch over oxidized corn starch to oxidized potato starch. All values were below $8 \mathrm{~kJ} / \mathrm{mol}$, therefore indicating physisorption.

In Figure $9 \mathrm{~b}$, the adsorption capacity of $\mathrm{Cd}^{2+}$ from $\mathrm{CdSO}_{4}$ solution is presented. Up to an initial concentration of $215 \mu \mathrm{mol} / \mathrm{L}$, the oxidized starches featured an excellent adsorption rate with almost complete $\mathrm{Cd}^{2+}$ adsorption. In comparison, the native potato starch showed high adsorption rates for $\mathrm{Cd}^{2+}$ at low initial concentrations up to $13 \mu \mathrm{mol} / \mathrm{L}$. The adsorption isotherms of native potato starch, oxidized corn starch, and oxidized potato starch were fitted with Langmuir, Sips, and Dubinin-Radushkevich models. The curves and fitting parameters of these three models for native potato starch, oxidized potato starch, and oxidized corn starch are given in Table 5 and Figure S23. The isotherm fitting with Sips model showed the highest values for $\mathrm{R}^{2}$ for the adsorption of $\mathrm{Cd}^{2+}$ yielding in the best fitting model (see Figure $9 \mathrm{~b}$ ). In general, the calculated maximum adsorption capacities $\left(15 \mu \mathrm{mol} \mathrm{Cd}{ }^{2+} / \mathrm{g}\right.$ native potato starch, $71 \mu \mathrm{mol} \mathrm{Cd} \mathrm{Cd}^{2+} / \mathrm{g}$ oxidized potato starch,

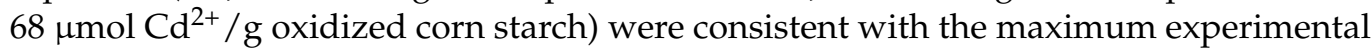
adsorption capacities. In comparison, the mean free energy values for the adsorption onto the different starch samples derived from the Dubinin-Radushkevich model showed almost equal values among the different starches. This indicates a similar affinity of the different starches toward $\mathrm{Cd}^{2+}$, although exhibiting different maximum adsorption capacities. Thus, this can be explained by differing heterogeneous distributions with different amounts of accessible active sites on the surface of the starch samples.

Table 5. Fitting parameters for Langmuir, Sips, and Dubinin-Radushkevich isotherm models for native potato starch, oxidized potato starch, and oxidized corn starch for adsorption from $\mathrm{CdSO}_{4}$ solution. $\mathrm{Qm}_{\mathrm{m}}$ thereby is the maximal sorption capacity, $\mathrm{K}$ is the equilibrium constant for the respective model, $\mathrm{n}$ is the Sips isotherm model exponent, and $\mathrm{E}_{\mathrm{ads}, \mathrm{DR}}$ is the mean free energy of adsorption derived from the Dubinin-Radushkevich model. None of the applied models gave a reasonable fit to the isotherm of native corn starch.

\begin{tabular}{|c|c|c|c|c|c|c|c|}
\hline Sample & Model & $\underset{\mu \mathrm{mol} / \mathrm{g}}{\mathrm{Q}_{\mathrm{m}}}$ & $\underset{\mathrm{L} / \mu \mathrm{mol}}{\mathrm{K}}$ & $\underset{\mathrm{mol}^{2} / \mathrm{J}^{2}}{\beta_{\mathrm{DR}}}$ & $\mathbf{n}$ & $\begin{array}{l}E_{\text {ads,DR }} \\
\mathrm{kJ} / \mathrm{mol}\end{array}$ & $\mathbf{R}^{2}$ (COD) \\
\hline \multirow{3}{*}{ Native potato starch } & Langmuir & $10.4 \pm 0.7$ & $1.45 \pm 0.70$ & - & - & - & 0.831 \\
\hline & Sips & $14.6 \pm 6.5$ & $0.48 \pm 0.41$ & - & $0.3 \pm 0.2$ & - & 0.876 \\
\hline & Dubinin-Radushkevich & $10.3 \pm 0.7$ & - & $1.49 \cdot 10-7 \pm 8.4 \cdot 10-8$ & - & $1.83 \pm 0.52$ & 0.809 \\
\hline \multirow{3}{*}{ Oxidized potato starch } & Langmuir & $72.7 \pm 2.7$ & $0.72 \pm 0.11$ & - & - & - & 0.967 \\
\hline & Sips & $70.5 \pm 2.8$ & $0.72 \pm 0.12$ & - & $1.2 \pm 0.2$ & - & 0.970 \\
\hline & Dubinin-Radushkevich & $67.4 \pm 2.5$ & - & $3.40 \cdot 10-7 \pm 5.3 \cdot 10-8$ & - & $1.21 \pm 0.94$ & 0.955 \\
\hline \multirow{3}{*}{ Oxidized corn starch } & Langmuir & $63.6 \pm 1.7$ & $1.23 \pm 0.18$ & - & - & - & 0.980 \\
\hline & Sips & $68.1 \pm 2.2$ & $1.01 \pm 0.11$ & - & $0.7 \pm 0.1$ & - & 0.991 \\
\hline & Dubinin-Radushkevich & $60.0 \pm 2.5$ & - & $1.49 \cdot 10-7 \pm 8.4 \cdot 10-8$ & - & $1.84 \pm 0.20$ & 0.941 \\
\hline
\end{tabular}

After the adsorption experiment, the starch samples were rinsed with ultrapure water and subsequently investigated using SEM-EDX analysis with elemental mapping (Figure 10). The adsorption of $\mathrm{Cd}^{2+}$ occurred homogeneously among the surface of the starch samples. This is in agreement with the viable and relatively similar coefficient of determination derived from Langmuir and Sips adsorption models. The amounts of $\mathrm{Cd}^{2+}$ on native corn starch were below the detection limit in EDX, which was also in agreement with the lowest adsorption efficiency among the different starch samples.
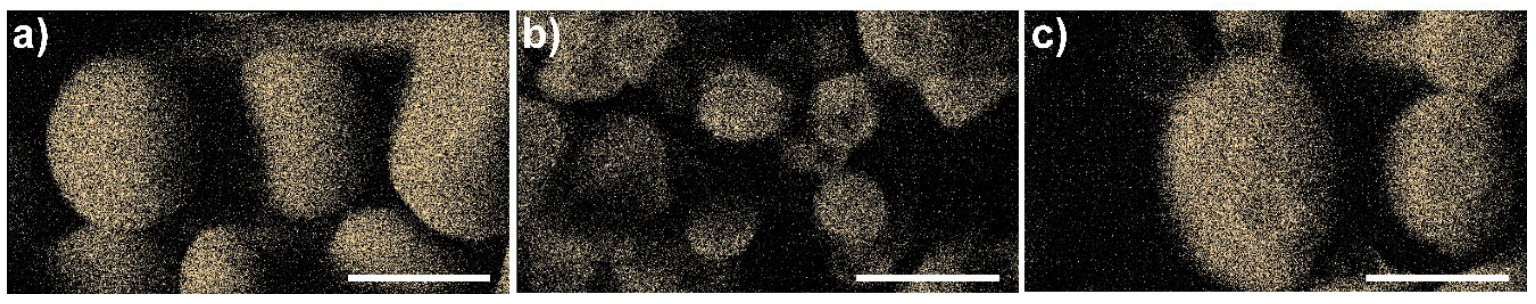

Figure 10. Elemental mapping derived from SEM-EDX from (a) native potato starch, (b) oxidized potato starch, and (c) oxidized corn starch after adsorption experiments with $\mathrm{CdSO}_{4}$ solution $\mathrm{Cd}$ in yellow at 10,000-fold magnification. For native corn starch, the adsorbed amounts of $\mathrm{Cd}^{2+}$ were below the detection limit for SEM-EDX. Scale bar is $15 \mu \mathrm{m}$. 
Additionally, the adsorption of $\mathrm{Pb}^{2+}$ from $\mathrm{PbSO}_{4}$ solution onto the native and oxidized potato and corn starches was investigated, and the results are depicted in Figure 11. Due to the low solubility of $\mathrm{PbSO}_{4}$, the maximum tested $\mathrm{Pb}^{2+}$ concentration was $190 \mu \mathrm{mol} / \mathrm{L}$. Within the complete range of concentrations, the oxidized starches showed a very high adsorption rate for $\mathrm{Pb}^{2+}$ of $>97 \%$. As shown in Figure 11a, no plateau was obtained for the oxidized starches. The n. potato starch showed high adsorption values for $\mathrm{Pb}^{2+}$ concentrations between 0.3 and $19 \mu \mathrm{mol} / \mathrm{L}(84-100 \%)$. Native corn starch exhibited an overall lower adsorption efficiency, as expected from the results shown in Section 3.2. The highest experimental adsorption capacities among the respective isotherms of native potato and corn starch were 15.0 and $5.5 \mu \mathrm{mol} / \mathrm{g}$, respectively. For the native starches, different fitting models could be applied. The fitting parameters are presented in Table 6 and the Sips isotherm fit is shown in Figure 11a featuring the highest $R^{2}$ value among all tested models.
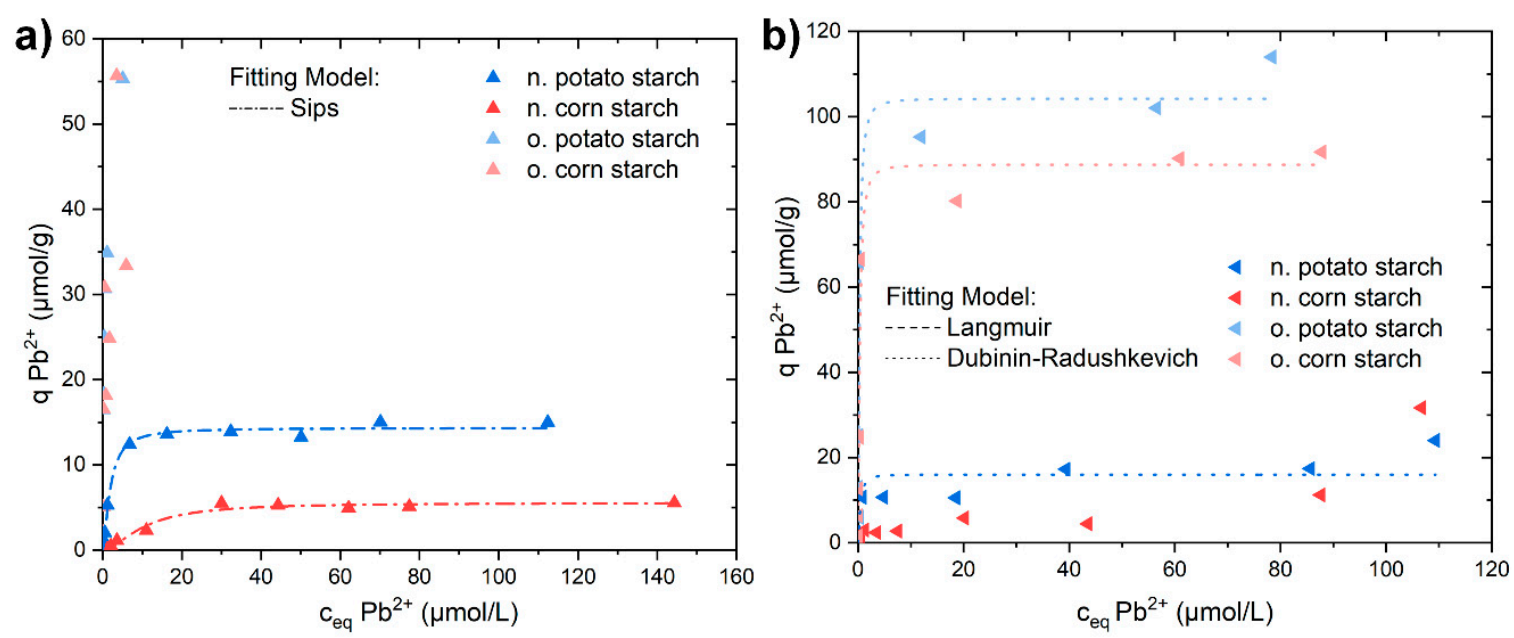

Figure 11. (a) Adsorption isotherm of $\mathrm{Pb}^{2+}$ from $\mathrm{PbSO}_{4}$ solution with adsorbent dosage of $100 \mathrm{mg} / 30 \mathrm{~mL}$ and corresponding Sips isotherm model fits. Native potato starch is shown in blue, native corn starch in red, oxidized potato starch in light blue, and oxidized corn starch in pink. The corresponding $\mathrm{SO}_{4}{ }^{2-}$ adsorption and $\mathrm{pH}$ values can be seen in Figure $\mathrm{S} 24$. (b) Adsorption isotherm of $\mathrm{Pb}^{2+}$ from $\mathrm{PbSO}_{4}$ solution with decreased adsorbent dosage of $10 \mathrm{mg} / 30 \mathrm{~mL}$ and corresponding Dubinin-Radushkevich isotherm model fits. Native potato starch is shown in blue, native corn starch in red, oxidized potato starch in light blue, and oxidized corn starch in pink. The corresponding $\mathrm{SO}_{4}{ }^{2-}$ adsorption and $\mathrm{pH}$ values can be seen in Figure S25.

Table 6. Fitting parameters for Langmuir, Sips, and Dubinin-Radushkevich isotherm models for native potato starch and native corn starch for $\mathrm{Pb}^{2+}$ adsorption from $\mathrm{PbSO}_{4}$ solution with adsorbent dosage of $100 \mathrm{mg} / 30 \mathrm{~mL}$. $\mathrm{Q}_{\mathrm{m}}$ thereby is the maximal sorption capacity, $\mathrm{K}$ is the equilibrium constant for the respective model, $\mathrm{n}$ is the Sips isotherm model exponent, and $\mathrm{E}_{\mathrm{ads}, \mathrm{DR}}$ is the mean free energy of adsorption derived from the Dubinin-Radushkevich model.

\begin{tabular}{|c|c|c|c|c|c|c|c|}
\hline Sample & Model & $\underset{\mu \mathrm{mol} / \mathrm{g}}{Q_{\mathrm{m}}}$ & $\underset{\mathrm{L} / \mu \mathrm{mol}}{\mathrm{K}}$ & $\begin{array}{c}\beta_{\mathrm{DR}} \\
\mathrm{mol}^{2} / \mathrm{J}^{2}\end{array}$ & $\mathbf{n}$ & $\begin{array}{l}E_{\text {ads,DR }} \\
\mathrm{kJ} / \mathrm{mol}\end{array}$ & $R^{2}(\mathrm{COD})$ \\
\hline \multirow{3}{*}{ Native potato starch } & Langmuir & $6.4 \pm 0.6$ & $0.07 \pm 0.02$ & - & - & - & 0.947 \\
\hline & Sips & $5.6 \pm 0.4$ & $0.02 \pm 0.02$ & - & $1.7 \pm 0.5$ & - & 0.971 \\
\hline & Dubinin-Radushkevich & $5.5 \pm 0.3$ & - & $1.68 \cdot 10-5 \pm 5.0 \cdot 10-6$ & - & $0.17 \pm 0.03$ & 0.950 \\
\hline \multirow{3}{*}{ Native corn starch } & Langmuir & $15.3 \pm 0.5$ & $0.39 \pm 0.07$ & - & - & - & 0.982 \\
\hline & Sips & $14.3 \pm 0.4$ & $0.38 \pm 0.06$ & - & $1.5 \pm 0.2$ & - & 0.992 \\
\hline & Dubinin-Radushkevich & $14.0 \pm 0.3$ & - & $4.04 \cdot 10-7 \pm 5.16 \cdot 10-8$ & - & $1.11 \pm 0.07$ & 0.987 \\
\hline
\end{tabular}

\section{4. $\mathrm{Pb}^{2+}$ Batch Adsorption Experiments with Decreased Adsorbent Dose}

To determine an adsorption capacity of the oxidized starch samples for the $\mathrm{Pb}^{2+}$ adsorption from $\mathrm{PbSO}_{4}$ solution, we carried out further batch adsorption experiments, using only $10 \mathrm{wt} \%$ of the originally $100 \mathrm{mg}$ adsorber material. The results for these adsorption isotherms are presented in Figure $11 \mathrm{~b}$. Up to a concentration of $22 \mu \mathrm{mol} / \mathrm{L}$, 
the oxidized starches exhibited an excellent adsorption with adsorption rates above $96 \%$. The presented adsorption curves showed maximum experimental adsorption capacities of 113 and $92 \mu \mathrm{mol} / \mathrm{g}$ for oxidized potato starch and oxidized corn starch, respectively. The fittings of the adsorption isotherms were performed using the Dubinin-Radushkevich model (see Figure 11b) (for fitting parameters see Table 7). Sips model gave no reasonable fitting for all isotherms. The coefficients of determination $\mathrm{R}^{2}$ for the respective Langmuir and Dubinin-Radushkevich models were relatively similar, whereby native potato starch showed better fitting with the Langmuir model and the oxidized starches with the DubininRadushkevich model.

Table 7. Fitting parameters for Langmuir, Sips, and Dubinin-Radushkevich isotherm models for adsorption with decreased adsorbent dose from $\mathrm{PbSO}_{4}$ solution. $\mathrm{Q}_{\mathrm{m}}$ thereby is the maximal sorption capacity, $\mathrm{K}$ is the equilibrium constant for the respective model, and $\mathrm{E}_{\mathrm{ads}, \mathrm{DR}}$ is the mean free energy of adsorption derived from the Dubinin-Radushkevich model. To the isotherm of native corn starch, no applied model gave a reasonable fit.

\begin{tabular}{|c|c|c|c|c|c|c|}
\hline Sample & Model & $\underset{\mu \mathrm{mol} / \mathrm{g}}{\mathrm{Q}_{\mathrm{m}}}$ & $\begin{array}{c}\mathrm{K} \\
\mathrm{L} / \mu \mathrm{mol}\end{array}$ & $\begin{array}{c}\beta_{\mathrm{DR}} \\
\mathrm{mol}^{2} / \mathrm{J}^{2}\end{array}$ & $\begin{array}{l}\mathrm{E}_{\mathrm{ads}, \mathrm{DR}} \\
\mathrm{kJ} / \mathrm{mol}\end{array}$ & $\mathrm{R}^{2}$ (COD) \\
\hline \multirow{2}{*}{ Native potato starch } & Langmuir & $17.1 \pm 2.0$ & $1.31 \pm 0.96$ & - & - & 0.770 \\
\hline & Dubinin-Radushkevich & $16.0 \pm 1.9$ & - & $7.79 \cdot 10^{-8} \pm 4.27 \cdot 10^{-8}$ & $2.53 \pm 0.69$ & 0.740 \\
\hline \multirow{2}{*}{ Oxidized potato starch } & Langmuir & $105.5 \pm 9.7$ & $2.78 \pm 1.25$ & - & - & 0.896 \\
\hline & Dubinin-Radushkevich & $104.2 \pm 9.4$ & - & $4.91 \cdot 10^{-8} \pm 1.30 \cdot 10^{-8}$ & $3.19 \pm 0.42$ & 0.898 \\
\hline \multirow{2}{*}{ Oxidized corn starch } & Langmuir & $89.5 \pm 6.1$ & $2.52 \pm 0.78$ & - & - & 0.941 \\
\hline & Dubinin-Radushkevich & $88.7 \pm 4.5$ & - & $5.86 \cdot 10^{-8} \pm 9.2 \cdot 10^{-9}$ & $2.92 \pm 0.23$ & 0.966 \\
\hline
\end{tabular}

Native potato starch exhibited a similar adsorption capacity as in the experiment before, confirming the obtained plateau in the experiments presented before (Figure 11a). For the oxidized potato and corn starch, maximum adsorption capacities of 106 and 90 $\mu \mathrm{mol} / \mathrm{g}$ were derived, respectively. With the increasing adsorption capacity in the order of native potato starch < oxidized corn starch < oxidized potato starch, the free energy of adsorption was found to be increasing too. Therefore, it can be concluded that oxidized potato starch exhibited the strongest adsorption interaction toward $\mathrm{Pb}^{2+}$.

The samples of the adsorption experiments treated with the highest $\mathrm{Pb}^{2+}$ concentrations were rinsed with ultrapure water and subsequently dried for investigation with SEM-EDX (Figure 12). For all the starches, a clustering of very high $\mathrm{Pb}^{2+}$ concentration occurred, indicating both a heterogeneous surface with potentially monolayer adsorption onto less active sites and a multilayer adsorption onto distinctive spots on the surface. These spots mainly featured low amounts of $\mathrm{S}$ in addition to the high amounts of $\mathrm{Pb}$ in the energy-dispersed spectra (see Figures S20 and S21, Tables S2 and S3).
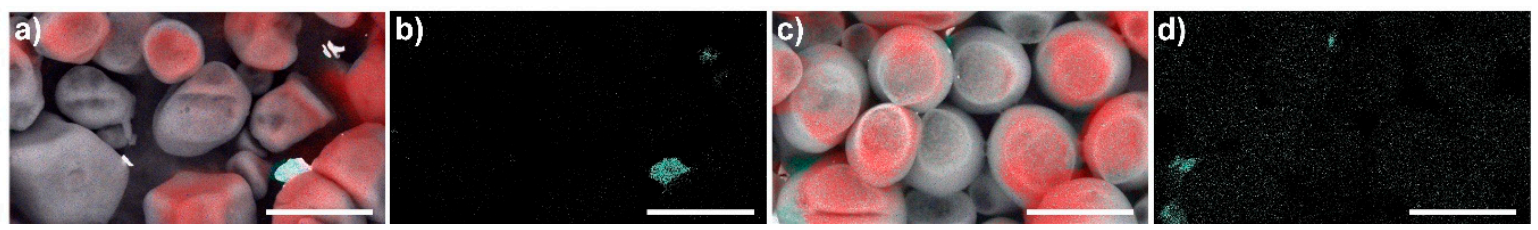

Figure 12. SEM-EDX elemental mapping of oxidized corn starch (a,b) and oxidized potato starch (c,d) at 10,000 fold magnification. $\mathrm{C}$ is shown in red, $\mathrm{O}$ in blue, and $\mathrm{Pb}$ in green. Scale bar is $15 \mu \mathrm{m}$.

Oxidized potato starch featured the highest adsorption capacities for $\mathrm{Pb}^{2+}, \mathrm{Cd}^{2+}$, and $\mathrm{Al}^{3+}$. In particular, the amount of aldehyde groups contributed to its very good adsorption performance. Oxidized corn starch also possessed relatively high adsorption capacities. The lower adsorption capacity compared to the oxidized potato starch could have been due to the higher $\mathrm{pH}$ dependency of the carboxylic group. In general, native potato starch and native corn starch featured a lower charge density and a lower number of functional groups. Thus, in comparison to the oxidized starches, both native starches exhibited lower maximum adsorption capacities. Among the native starch samples, native potato starch possessed the highest adsorption capacities with $23 \mu \mathrm{mol} \mathrm{Al}{ }^{3+} / \mathrm{g}, 15 \mu \mathrm{mol} \mathrm{Cd} \mathrm{C}^{2+} / \mathrm{g}$, 
and $17 \mu \mathrm{mol} \mathrm{Pb}^{2+} / \mathrm{g}$. Furthermore, the already improved adsorption properties of the native potato starch in comparison to the other native starches might have also had an influence on the high adsorption capacities of the oxidized potato starch. Additionally, native potato starch and the oxidized starches showed very good adsorption rates for the lower concentrations in the ppm range.

The achieved maximum adsorption capacities were compared with the literature (see Supplementary Information, Tables S4-S6). The oxidized starch samples surpassed most of the abundantly available, unmodified bioadsorbers such as algae or bacteria. For the first time, we successfully present the adsorption of $\mathrm{Al}^{3+}$ onto native and oxidized starches in acidic $\mathrm{pH}$ range.

\section{5. $\mathrm{Al}^{3+}$ Sorption Experiments with Real Water Samples}

To simulate natural conditions, we considered testing surface water to evaluate the starch absorption ability of metal ions. The three investigated real water samples were first analyzed with ICP-OES, $\mathrm{pH}$, and conductivity measurements (see Table 8 and Figures S26 and S27). All three real water samples contained elevated levels of $\mathrm{Al}^{3+}$ and very low levels of $\mathrm{Pb}^{2+}$ (see Table 8). Only the adsorption of $\mathrm{Al}^{3+}$ is discussed, as the very low initial concentration of $\mathrm{Pb}^{2+}$ (and $\mathrm{Cd}^{2+}$ in water 1 ) is prone to errors, especially under non-ideal conditions such as in real water samples. Furthermore, these samples also contained a considerable amount of sulfate, which exceeded the German Drinking Water ordinance limit for sulfate $(250 \mathrm{mg} / \mathrm{L}$; [69]) up to a factor of 1.6. Additionally, the samples exhibited highly acidic pH values between 3.4 and 3.8 (see Figures S28-S30).

Table 8. Amount of sulfate and heavy metal ions in the real water sample and values for $\mathrm{pH}$, conductivity, and solid content.

\begin{tabular}{cccccc}
\hline Sample & $\begin{array}{c}\mathrm{SO}_{4}{ }^{2-} \\
(\mathbf{m g} / \mathbf{L})\end{array}$ & $\begin{array}{c}\mathbf{C d}^{2+} \\
(\mathbf{m g} / \mathbf{L})\end{array}$ & $\begin{array}{c}\mathbf{A l}^{3+} \\
(\mathbf{m g} / \mathbf{L})\end{array}$ & $\begin{array}{c}\mathbf{P b}^{2+} \\
(\mathbf{m g} / \mathbf{L})\end{array}$ & $\mathbf{p H}_{\mathbf{0}}$ \\
\hline Water 1 & 446.95 & 0.01 & 2.16 & 0.06 & 3.4 \\
\hline Water 2 & 374.80 & 0.00 & 1.68 & 0.02 & 3.7 \\
\hline Water 3 & 367.43 & 0.00 & 1.87 & 0.02 & 3.8 \\
\hline
\end{tabular}

In all cases, the adsorption of the positively charged $\mathrm{Al}^{3+}$ was successful, while the adsorption performance of the negatively charged starch toward sulfate ions were negligible as expected from the experiments with simulated water (see Figure S28). Figure 13 shows the results of $\mathrm{Al}^{3+}$ adsorption onto the six diverse starch samples. Even under these non-laboratory conditions, the results showed viable separation of $\mathrm{Al}^{3+}$ from the water. As the real water samples also contained solid materials, other competitive ions (e.g., $\mathrm{Cu}^{2+}, \mathrm{Fe}^{2+/ 3+}, \mathrm{Mn}^{\mathrm{n}+}, \mathrm{PO}_{4}{ }^{3-}$ ), and dissolved organic matter, a decreased adsorption rate compared to the simulated wastewaters seems reasonable. The native potato starch adsorbed $21 \%$ of $\mathrm{Al}^{3+}$ (Figure 13a), which was lower than in the adsorption from simulated waters $\left(83 \%\right.$ from $\left.1 \mathrm{mg} / \mathrm{L} \mathrm{Al}^{3+}\right)$. For the oxidized corn starch, a similar trend was visible: Its adsorption performance decreased from $92 \%$ of the initial $1 \mathrm{mg} / \mathrm{L} \mathrm{Al}^{3+}$ in the simulated water to $19 \%$ in the real water experiment (Figure 13a). This could have been due to other competing ions and the lower initial $\mathrm{pH}_{0}$ of 3.4 in the real water samples vs. an initial $\mathrm{pH}$ of 7.4 in the laboratory conditions (see Figure S27) sites. Especially in the case of oxidized corn starch, this acidic $\mathrm{pH}$ decreased the deprotonation of carboxylic groups, leading to a lower charge density (see Figure $1 \mathrm{~b}$ ) and adsorption performance.

In general, the adsorption rates for the six investigated starches obtained for the real water samples confirmed the results from the simulated water experiments. Except for $\mathrm{n}$. potato starch, the native starches showed negligible adsorption rates for $\mathrm{Al}^{3+}$. Furthermore, similar to the simulated water, o. potato starch featured the highest adsorption rates among all six starches. Thus, we proved a successful adsorption process with real water samples, despite many other substances, which were present in the real water samples and the 
significantly lower initial $\mathrm{pH}$ value. Especially oxidized potato starch with its aldehyde and keto groups featured excellent $\mathrm{Al}^{3+}$ removal that was independent of the initial $\mathrm{pH}$.
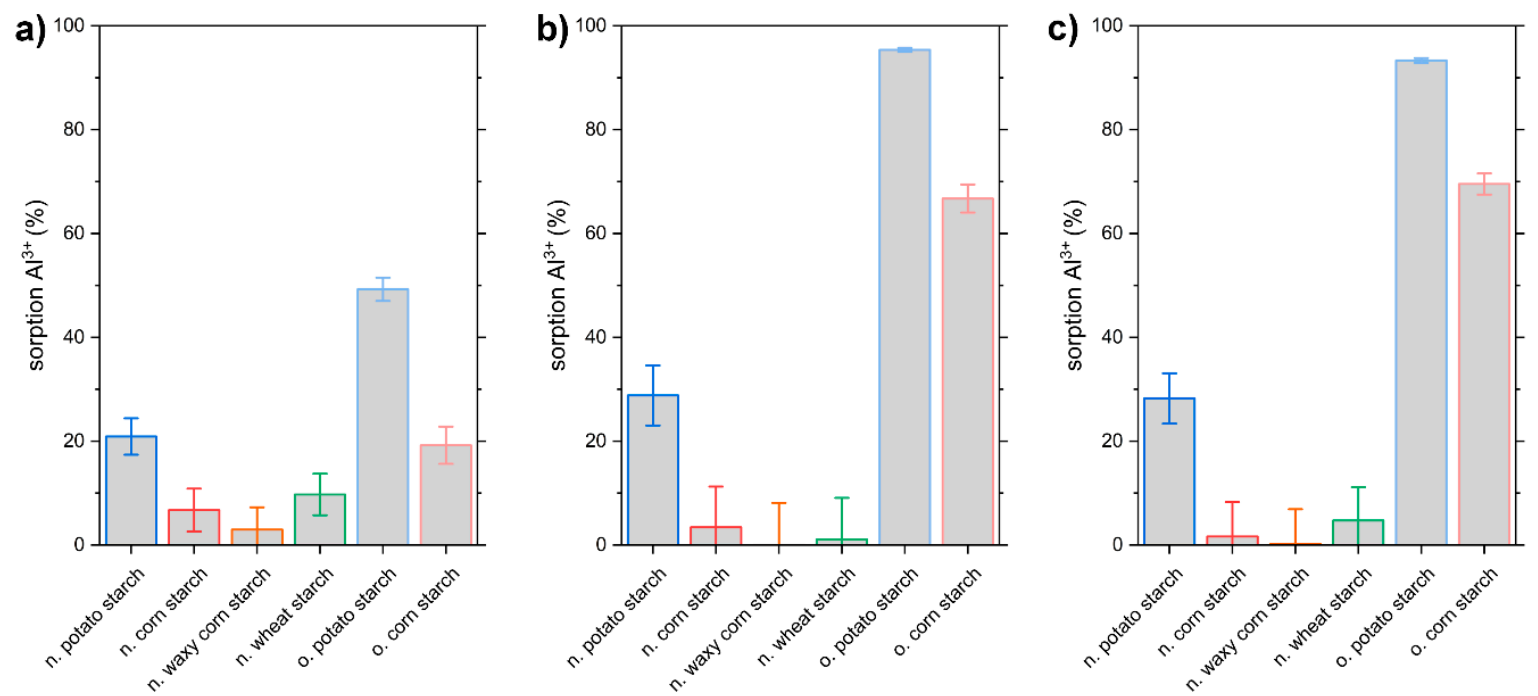

Figure 13. Adsorption experiment with $\mathrm{Al}^{3+}$ in water samples. (a) Adsorption experiment with $\mathrm{Al}^{3+}$ in water 1 with an initial concentration of aluminum ions of $2.16 \mathrm{mg} / \mathrm{L}$. (b) Adsorption experiment with $\mathrm{Al}^{3+}$ in water 2 with an initial concentration of aluminum ions of $0.84 \mathrm{mg} / \mathrm{L}$. (c) Adsorption experiment with $\mathrm{Al}^{3+}$ in water 3 with an initial concentration of aluminum ions of $0.94 \mathrm{mg} / \mathrm{L}$ on native potato starch (blue), native corn starch (red), native waxy corn starch (orange), native wheat starch (green), oxidized potato starch (light blue), and oxidized corn starch (pink). The corresponding $\mathrm{pH}$ values for the real water samples are shown in Figures S28-S30 and the corresponding $\mathrm{SO}_{4}{ }^{2-}$ percentage adsorption is shown in Figures S31-S33. The adsorption experiments with water 1 were conducted with an adsorption time of two hours, while $24 \mathrm{~h}$ was chosen for water 2 and 3.

\section{Conclusions}

In this article, we investigated four different native and two oxidized starch samples with respect to their application as suitable adsorber materials for water treatment. The adsorption performance of all six starch samples for $\mathrm{Al}^{3+}, \mathrm{Cd}^{2+}$, and $\mathrm{Pb}^{2+}$ was investigated. The adsorption rates for the four diverse native starches featured significant differences showing a distinct improved adsorption performance for all three metal ions $\left(\mathrm{Al}^{3+}, \mathrm{Cd}^{2+}\right.$, and $\mathrm{Pb}^{2+}$ ) for $\mathrm{n}$. potato starch. Particular effort was devoted to the low concentration regions, which are important for the management of water quality. Furthermore, we are the first to report on the adsorption of $\mathrm{Al}^{3+}$ on starch samples in an acidic $\mathrm{pH}$ range. Both oxidized starches and native potato starch featured excellent adsorption properties, especially in the low concentration ranges, and therefore are potential viable adsorber materials for $\mathrm{Al}^{3+}, \mathrm{Cd}^{2+}$, and $\mathrm{Pb}^{2+}$. Furthermore, oxidized starches outperformed the native starches, especially at higher pollutant concentrations. Nonetheless, due to their low cost, also native starches such as, e.g., the here-presented potato starch can be applied to improve water quality of aquatic ecosystems or natural water reservoirs due to their high adsorption rates in low concentration regions, their low cost, and their natural abundance. Oxidized potato starch systematically featured the highest adsorption rates and capacities for all three metal ions among the investigated starches. The improved adsorption performance of o. potato starch in comparison to $\mathrm{o}$. corn starch might have been due to the already good properties and adsorption rates of the native potato starch, relative to the other native starch samples.

Supplementary Materials: The following are available online at https:/ / www.mdpi.com/article/ $10.3390 /$ polysaccharides2020027/s1, Figure S1. Integrals of H1 $(\alpha 1,4)+H 1(t)$ and H1 $(\alpha 1,6)$ from oxidized potato starch. Figure S2. ATR-FTIR spectra of the solid native potato starch (blue), native corn starch (red), native waxy corn starch (orange), native wheat starch (green), oxidized potato 
starch (light blue), and oxidized corn starch (pink). Figure S3. Moisture analysis of the samples carried out at $150^{\circ} \mathrm{C}$. Figure S4. Particle size distribution of the starch samples in dry state. Figure S5. (a) SEM images and SEM-EDX elemental mappings from native potato starch; (b) sum spectrum (blue) and maximum pixel spectrum (red). Figure S6. (a) SEM images and SEM-EDX elemental mappings from native corn starch; (b) sum spectrum (blue) and maximum pixel spectrum (red). Figure S7. (a) SEM images and SEM-EDX elemental mappings from native waxy corn starch; (b) sum spectrum (blue) and as maximum pixel spectrum (red). Figure S8. (a) SEM images and SEM-EDX elemental mappings from native wheat starch; (b) sum spectrum (blue) and maximum pixel spectrum (red). Figure S9. (a) SEM images and SEM-EDX elemental mappings from oxidized potato starch; (b) sum spectrum (blue) and maximum pixel spectrum (red). Figure S10. (a) SEM images and SEM-EDX elemental mappings from oxidized corn starch; (b) sum spectrum (blue) and maximum pixel spectrum (red). Figure S11. (a) Nitrogen sorption isotherms at $77 \mathrm{~K}$ and (b) carbon dioxide sorption isotherms at $273 \mathrm{~K}$ of native potato starch (blue), native corn starch (red), native waxy corn starch (orange), native wheat starch (green), oxidized potato starch (light blue), and oxidized corn starch (pink). Figure S12. $\mathrm{pH}$ values for the experiments with $\mathrm{Al}_{2}\left(\mathrm{SO}_{4}\right)_{3}$ solution of $0.11 \mathrm{mg} / \mathrm{L}$ and $1.09 \mathrm{mg} / \mathrm{L} \mathrm{Al}^{3+}$ before $\left(\mathrm{pH}_{0}\right)$ and after $\left(\mathrm{pH}_{\mathrm{eq}}\right)$ the adsorption process of native potato starch (blue), native corn starch (red), native waxy corn starch (orange), native wheat starch (green), oxidized potato starch (light blue), and oxidized corn starch (pink). $\mathrm{pH}_{0}$ corresponds to the $\mathrm{pH}$ value of the adsorptive solution before the experiment and $\mathrm{pH}_{\mathrm{eq}}$ corresponds to the $\mathrm{pH}$ value after the adsorption process. Figure S13. $\mathrm{pH}$ values for the experiments with $\mathrm{CdSO}_{4}$ solution of $0.11 \mathrm{mg} / \mathrm{L}$ and $1.12 \mathrm{mg} / \mathrm{L} \mathrm{Cd}^{2+}$ before $\left(\mathrm{pH}_{0}\right)$ and after $\left(\mathrm{pH}_{\mathrm{eq}}\right)$ the adsorption process of native potato starch (blue), native corn starch (red), native waxy corn starch (orange), native wheat starch (green), oxidized potato starch (light blue), and oxidized corn starch (pink). $\mathrm{pH}_{0}$ corresponds to the $\mathrm{pH}$ value of the adsorptive solution before the experiment and $\mathrm{pH}_{\mathrm{eq}}$ corresponds to the $\mathrm{pH}$ value after the adsorption process. Figure S14. $\mathrm{pH}$ values for the experiments with $\mathrm{PbSO}_{4}$ solution of $0.08 \mathrm{mg} / \mathrm{L}$ and $0.91 \mathrm{mg} / \mathrm{L} \mathrm{Pb}^{2+}$ before $\left(\mathrm{pH}_{0}\right)$ and after $\left(\mathrm{pH}_{\mathrm{eq}}\right)$ the adsorption process of native potato starch (blue), native corn starch (red), native waxy corn starch (orange), native wheat starch (green), oxidized potato starch (light blue), and oxidized corn starch (pink). $\mathrm{pH}_{0}$ corresponds to the $\mathrm{pH}$ value of the adsorptive solution before the experiment and $\mathrm{pH}_{\mathrm{eq}}$ corresponds to the $\mathrm{pH}$ value after the adsorption process. Figure S15. Percentage adsorption of $\mathrm{SO}_{4}{ }^{2-}$ ions from (a) $\mathrm{Al}_{2}\left(\mathrm{SO}_{4}\right)_{3}$ adsorption experiments with an initial concentration of aluminum ions of $0.11 \mathrm{mg} / \mathrm{L}$ (solid) and $1.09 \mathrm{mg} / \mathrm{L}$ (striped); (b) $\mathrm{CdSO}_{4}$ adsorption experiments with an initial concentration of cadmium ions of $0.11 \mathrm{mg} / \mathrm{L}$ (solid) and $1.12 \mathrm{mg} / \mathrm{L}$ (striped); (c) $\mathrm{PbSO}_{4}$ adsorption experiments with an initial concentration of lead ions of $0.08 \mathrm{mg} / \mathrm{L}$ (solid) and $0.91 \mathrm{mg} / \mathrm{L}$ (striped) onto native potato starch (blue), native corn starch (red), native waxy corn starch (orange), native wheat starch (green), oxidized potato starch (light blue), and oxidized corn starch (pink) in screening experiments with $\mathrm{Al}^{3+}, \mathrm{Pb}^{2+}$, and $\mathrm{Cd}^{2+}$. Figure $\mathrm{S} 16$. (a) $\mathrm{SO}_{4}{ }^{2-}$ percentage adsorption and (b) corresponding $\mathrm{pH}_{0}$ and $\mathrm{pH}_{\mathrm{eq}}$ values from adsorption of $\mathrm{Al}_{2}\left(\mathrm{SO}_{4}\right)_{3}$ solution onto the starch samples with native potato starch (blue), native corn starch (red), oxidized potato starch (light blue), and oxidized corn starch (pink). $\mathrm{pH}_{0}$ (black) corresponds to the $\mathrm{pH}$ value of the adsorptive solution before the experiment and $\mathrm{pH}_{\mathrm{eq}}$ corresponds to the $\mathrm{pH}$ value after the adsorption process. Figure S17. (a) $\mathrm{SO}_{4}{ }^{2-}$ percentage adsorption and (b) corresponding $\mathrm{pH}_{0}$ and $\mathrm{pH}_{\mathrm{eq}}$ values from adsorption of $\mathrm{CdSO}_{4}$ solution onto the starch samples with native potato starch (blue), native corn starch (red), oxidized potato starch (light blue), and oxidized corn starch (pink). $\mathrm{pH}_{0}$ (black) corresponds to the $\mathrm{pH}$ value of the adsorptive solution before the experiment and $\mathrm{pH}_{\mathrm{eq}}$ corresponds to the $\mathrm{pH}$ value after the adsorption process. Figure S18. (a) $\mathrm{SO}_{4}{ }^{2-}$ percentage adsorption and (b) corresponding $\mathrm{pH}_{0}$ and $\mathrm{pH}_{\mathrm{eq}}$ values from adsorption of $\mathrm{PbSO}_{4}$ solution onto the starch samples with native potato starch (blue), native corn starch (red), oxidized potato starch (light blue), and oxidized corn starch (pink). $\mathrm{pH}_{0}$ (black) corresponds to the $\mathrm{pH}$ value of the adsorptive solution before the experiment and $\mathrm{pH}_{\mathrm{eq}}$ corresponds to the $\mathrm{pH}$ value after the adsorption process. Figure S19. (a) $\mathrm{SO}_{4}{ }^{2-}$ percentage adsorption and (b) corresponding $\mathrm{pH}_{0}$ and $\mathrm{pH}_{\mathrm{eq}}$ values from adsorption of $\mathrm{PbSO}_{4}$ solution onto $10 \mathrm{mg}$ of the starch samples with native potato starch (blue), native corn starch (red), oxidized potato starch (light blue), and oxidized corn starch (pink). $\mathrm{pH}_{0}$ (black) corresponds to the $\mathrm{pH}$ value of the adsorptive solution before the experiment and $\mathrm{pH}_{\mathrm{eq}}$ corresponds to the $\mathrm{pH}$ value after the adsorption process. Figure S20. SEM image of oxidized potato starch (10 mg/30 mL adsorbent dose) after adsorption experiment with $\mathrm{PbSO}_{4}$ solution at 1000 -fold magnification with the location of the following spot analysis by EDS. Figure S21. SEM image of oxidized corn starch (10 mg/30 mL adsorbent dose) after adsorption experiment with $\mathrm{PbSO}_{4}$ 
solution at 1000-fold magnification with the location of the following spot analysis by EDS. Figure S22. Comparison of isotherms fitted for the Langmuir, Sips, and Dubinin-Radushkevich models for the adsorption of $\mathrm{Al}^{3+}$ from $\mathrm{Al}_{2}\left(\mathrm{SO}_{4}\right)_{3}$ solution with native potato starch (blue), oxidized potato starch (light blue), and oxidized corn starch (pink). Native corn starch (red) did not exhibit a viable fitting for the above-mentioned models. Figure S23. Comparison of isotherms fitted for the Langmuir, Sips, and Dubinin-Radushkevich models for the adsorption of $\mathrm{Cd}^{2+}$ from $\mathrm{CdSO}_{4}$ solution with native potato starch (blue), oxidized potato starch (light blue), and oxidized corn starch (pink). Native corn starch (red) did not exhibit a viable fitting for the above-mentioned models $\left(\mathrm{R}^{2}<0.7\right)$. Figure S24. Comparison of isotherms fitted for the Langmuir, Sips, and Dubinin-Radushkevich models for the adsorption of $\mathrm{Pb}^{2+}$ from $\mathrm{PbSO}_{4}$ solution with adsorbent doses of $100 \mathrm{mg} / 30 \mathrm{~mL}$ of the respective starch. Native potato starch is shown in blue and native corn starch in red. Oxidized corn starch (pink) and oxidized potato starch (light blue) were not fitted due to not reaching a plateau. Figure S25. Comparison of isotherms fitted for the Langmuir and Dubinin-Radushkevich models for the adsorption of $\mathrm{Pb}^{2+}$ from $\mathrm{PbSO}_{4}$ solution with decreased amounts (10 mg each) of native potato starch (blue), oxidized potato starch (light blue), and oxidized corn starch (pink). Native corn starch (red) did not exhibit a viable fitting for the above-mentioned models. Figure S26. (a) Streaming potential vs. $\mathrm{pH}$ curves and (b) charge densities at $\mathrm{pH}$ value of 3.6 of water 2 (brown) and water 3 (red). Figure S27. (a) pH values for the water samples with water 2 is shown in brown and water 3 is shown in red; (b) solid content in percentage in water 2 and water 3; (c) electrical conductivity of water 2 and 3. Figure S28. $\mathrm{pH}_{0}$ and $\mathrm{pH}_{\mathrm{eq}}$ values from adsorption of $\mathrm{Al}^{3+}$ onto the starch samples in real water 1 with native potato starch (blue), native corn starch (red), oxidized potato starch (light blue), and oxidized corn starch (pink). $\mathrm{pH}_{0}$ corresponds to the $\mathrm{pH}$ value of the adsorptive solution before the experiment and $\mathrm{pH}_{\mathrm{eq}}$ corresponds to the $\mathrm{pH}$ value after the adsorption process. Figure S29. $\mathrm{pH}_{0}$ and $\mathrm{pH}_{\mathrm{eq}}$ values from adsorption of $\mathrm{Al}^{3+}$ onto the starch samples in real water 2 with native potato starch (blue), native corn starch (red), oxidized potato starch (light blue), and oxidized corn starch (pink). $\mathrm{pH}_{0}$ corresponds to the $\mathrm{pH}$ value of the adsorptive solution before the experiment and $\mathrm{pH}_{\mathrm{eq}}$ corresponds to the $\mathrm{pH}$ value after the adsorption process. Figure $\mathrm{S} 30 . \mathrm{pH}_{0}$ and $\mathrm{pH}_{\mathrm{eq}}$ values from adsorption of $\mathrm{Al}^{3+}$ onto the starch samples in real water 3 with native potato starch (blue), native corn starch (red), oxidized potato starch (light blue), and oxidized corn starch (pink). $\mathrm{pH}_{0}$ corresponds to the $\mathrm{pH}$ value of the adsorptive solution before the experiment, and $\mathrm{pH}_{\mathrm{eq}}$ corresponds to the $\mathrm{pH}$ value after the adsorption process. Figure $\mathrm{S} 31 . \mathrm{SO}_{4}{ }^{2-}$ percentage adsorption onto the starch samples in real water 1 with native potato starch (blue), native corn starch (red), oxidized potato starch (light blue), and oxidized corn starch (pink). Moreover, for reference, one blind sample without added adsorber material is presented (black and dashed horizontal line). Figure S32. $\mathrm{SO}_{4}{ }^{2-}$ percentage adsorption onto the starch samples in real water 2 with native potato starch (blue), native corn starch (red), oxidized potato starch (light blue), and oxidized corn starch (pink). Moreover, for reference, one blind sample without added adsorber material is presented (black and dashed horizontal line). Figure S33. $\mathrm{SO}_{4}{ }^{2-}$ percentage adsorption onto the starch samples in real water 3 with native potato starch (blue), native corn starch (red), oxidized potato starch (light blue), and oxidized corn starch (pink). Moreover, for reference, one blind sample without added adsorber material is presented (black and dashed horizontal line). Table S1. FTIR vibration modes [1-3] for the starch samples. Table S2. Relative atomic concentration derived from spot analyses (location in Figure S20) at oxidized potato starch (10 mg/30 mL adsorbent dose) after adsorption experiment with $\mathrm{PbSO}_{4}$ solution. Table S3. Relative atomic concentration derived from spot analyses (location in Figure S21) at oxidized corn starch (10 mg/30 mL adsorbent dose) after adsorption experiment with $\mathrm{PbSO}_{4}$ solution. Table S4. Sorption capacities for removal of $\mathrm{Al}^{3+}$ compounds from aqueous solutions with different sorbent materials and adsorbent doses (a.d.). The obtained sorption capacities from this work were achieved in the batch adsorption experiments. Table S5. Sorption capacities for removal of $\mathrm{Cd}^{2+}$ compounds from aqueous solutions with different sorbent materials and adsorbent doses (a.d.). The obtained sorption capacities from this work were achieved in the batch adsorption experiments. Table S6. Sorption capacities for removal of $\mathrm{Pb}^{2+}$ compounds from aqueous solutions with different sorbent materials and adsorbent doses (a.d.). The obtained sorption capacities from this work were achieved in the batch adsorption experiments.

Author Contributions: Methodology, C.S.; formal analysis, R.B. (Regine Boldt), C.S., R.B. (Rahma Boughanmi), K.B.L.B. and B.R.; investigation, R.B. (Regine Boldt), C.S., R.B. (Rahma Boughanmi), P.G., K.B.L.B., B.R. and P.Z.; writing—original draft preparation, R.B. (Rahma Boughanmi), K.B.L.B. and B.R.; 
writing-review and editing, A.S., J.S., S.S., M.M, D.S., C.S., R.B. (Rahma Boughanmi), K.B.L.B., B.R. and P.Z.; visualization, R.B. (Rahma Boughanmi), C.S., D.S. and K.B.L.B.; supervision, S.S. and D.S.; project administration, M.M. and S.S.; funding acquisition, M.M. and S.S. All authors discussed the results and commented on the manuscript. All authors have read and agreed to the published version of the manuscript.

Funding: The authors gratefully acknowledge the support received from the Saxonian funding organization SAB and LfULG within the cooperative projects entitled "Development of environmentally compatible biopolymers as flocculants/adsorbents for the removal of iron and sulfate ions from surface waters" (SAB no 100377122) and "Mobile sensor systems for on-site heavy metal detection in water" (contract 33-8128/157/1), respectively.

Institutional Review Board Statement: Not applicable.

Informed Consent Statement: Not applicable.

Data Availability Statement: All findings discussed are based on the data contained within this current study.

Acknowledgments: The authors thank AGRANA Research and Innovation Center GmbH from Tulln, Austria, for the support of the materials, discussions, and cooperativeness. The authors also gratefully thank Marina Oelmann for particle size measurements, Eileen Schierz and Roland Schulze for elemental analysis measurements, and Egon Höfgen for characterization of real water samples. Both institutes (IPF Dresden and KSI Meinsberg) gratefully acknowledge the co-financing by tax funds on the basis of the budget passed by the Saxon state parliament.

Conflicts of Interest: The authors declare no conflict of interest.

\section{References}

1. Kumar, V.; Parihar, R.D.; Sharma, A.; Bakshi, P.; Sidhu, G.P.S.; Bali, A.S.; Karaouzas, I.; Bhardwaj, R.; Thukral, A.K.; Gyasi-Agyei, Y.; et al. Global evaluation of heavy metal content in surface water bodies: A meta-analysis using heavy metal pollution indices and multivariate statistical analyses. Chemosphere 2019, 236, 124364. [CrossRef] [PubMed]

2. Zhou, Q.; Yang, N.; Li, Y.; Ren, B.; Ding, X.; Bian, H.; Yao, X. Total concentrations and sources of heavy metal pollution in global river and lake water bodies from 1972 to 2017. Glob. Ecol. Conserv. 2020, 22, e00925. [CrossRef]

3. Soto, D.; Urdaneta, J.; Pernía, K.; León, O.; Muñoz-Bonilla, A.; Fernandez-García, M. Removal of heavy metal ions in water by starch esters. Starch Stärke 2015, 68, 37-46. [CrossRef]

4. Anghel, N.; Marius, N.; Spiridon, I. Heavy metal adsorption ability of a new composite material based on starch strengthened with chemically modified cellulose. Polym. Adv. Technol. 2019, 30, 1453-1460. [CrossRef]

5. El-Hamshary, H.; Fouda, M.M.G.; Moydeen, M.; Al-Deyab, S.S. Removal of heavy metal using poly (N-vinylimidazole)-graftedcarboxymethylated starch. Int. J. Biol. Macromol. 2014, 66, 289-294. [CrossRef]

6. Garcia, M.A.V.T.; Garcia, C.F.; Faraco, A.A.G. Pharmaceutical and Biomedical Applications of Native and Modified Starch: A Review. Starch Stärke 2020, 72, 1900270. [CrossRef]

7. Gui, Q.; Ouyang, Q.; Xu, C.; Ding, H.; Shi, S.; Chen, X. Facile and Safe Synthesis of Novel Self-Pored Amine-Functionalized Polystyrene with Nanoscale Bicontinuous Morphology. Int. J. Mol. Sci. 2020, 21, 9404. [CrossRef] [PubMed]

8. Crini, G. Recent developments in polysaccharide-based materials used as adsorbents in wastewater treatment. Prog. Polym. Sci. 2005, 30, 38-70. [CrossRef]

9. De Gisi, S.; Lofrano, G.; Grassi, M.; Notarnicola, M. Characteristics and adsorption capacities of low-cost sorbents for wastewater treatment: A review. Sustain. Mater. Technol. 2016, 9, 10-40. [CrossRef]

10. Nasrollahzadeh, M.; Sajjadi, M.; Iravani, S.; Varma, R.S. Starch, cellulose, pectin, gum, alginate, chitin and chitosan derived (nano)materials for sustainable water treatment: A review. Carbohydr. Polym. 2020, 251, 116986. [CrossRef]

11. Weißpflog, J.; Gündel, A.; Vehlow, D.; Steinbach, C.; Müller, M.; Boldt, R.; Schwarz, S.; Schwarz, D. Solubility and Selectivity Effects of the Anion on the Adsorption of Different Heavy Metal Ions onto Chitosan. Molecules 2020, 25, 2482. [CrossRef] [PubMed]

12. Ghiorghita, C.-A.; Borchert, K.B.L.; Vasiliu, A.-L.; Zaharia, M.-M.; Schwarz, D.; Mihai, M. Porous thiourea-grafted-chitosan hydrogels: Synthesis and sorption of toxic metal ions from contaminated waters. Colloids Surfaces A Physicochem. Eng. Asp. 2020, 607, 125504. [CrossRef]

13. Zhao, D.; Yu, S.; Sun, B.; Gao, S.; Guo, S.; Zhao, K. Biomedical Applications of Chitosan and Its Derivative Nanoparticles. Polymers 2018, 10, 462. [CrossRef]

14. Borchert, K.B.L.; Steinbach, C.; Schwarz, S.; Schwarz, D. A Comparative Study on the Flocculation of Silica and China Clay with Chitosan and Synthetic Polyelectrolytes. Mar. Drugs 2021, 19, 102. [CrossRef] [PubMed]

15. Wei, H.; Gao, B.; Ren, J.; Li, A.; Yang, H. Coagulation/flocculation in dewatering of sludge: A review. Water Res. 2018, 143, 608-631. [CrossRef] [PubMed] 
16. Song, Z.; Li, G.; Guan, F.; Liu, W. Application of Chitin/Chitosan and Their Derivatives in the Papermaking Industry. Polymers 2018, 10, 389. [CrossRef]

17. van den Broek, L.A.M.; Boeriu, C.G.; Stevens, C.V. (Eds.) Chitin and Chitosan: Properties and Applications; Wiley: Hoboken, NJ, USA, 2020; ISBN 978-1-119-45043-6.

18. Da Silva, S.B.; Batista, G.L.; Santin, C.K. Chitosan for Sensors and Electrochemical Applications. In Chitin and Chitosan: Properties and Applications; van den Broek, L.A.M., Boeriu, C.G., Stevens, C.V., Eds.; Wiley: Hoboken, NJ, USA, 2020; pp. 461-476. ISBN 978-1-119-45043-6.

19. Suginta, W.; Khunkaewla, P.; Schulte, A. Electrochemical Biosensor Applications of Polysaccharides Chitin and Chitosan. Chem. Rev. 2013, 113, 5458-5479. [CrossRef] [PubMed]

20. Ahmad, M.; Zhang, B.; Wang, J.; Xu, J.; Manzoor, K.; Ahmad, S.; Ikram, S. New method for hydrogel synthesis from diphenylcarbazide chitosan for selective copper removal. Int. J. Biol. Macromol. 2019, 136, 189-198. [CrossRef]

21. Manzoor, K.; Ahmad, M.; Ahmad, S.; Ikram, S. Synthesis, Characterization, Kinetics, and Thermodynamics of EDTA-Modified Chitosan-Carboxymethyl Cellulose as Cu(II) Ion Adsorbent. ACS Omega 2019, 4, 17425-17437. [CrossRef]

22. Wang, R.; Liang, R.; Dai, T.; Chen, J.; Shuai, X.; Liu, C. Pectin-based adsorbents for heavy metal ions: A review. Trends Food Sci. Technol. 2019, 91, 319-329. [CrossRef]

23. Bratskaya, S.Y.; Genest, S.; Petzold-Welcke, K.; Heinze, T.; Schwarz, S. Flocculation Efficiency of Novel Amphiphilic Starch Derivatives: A Comparative Study. Macromol. Mater. Eng. 2013, 299, 722-728. [CrossRef]

24. Krentz, D.-O.; Lohmann, C.; Schwarz, S.; Bratskaya, S.; Liebert, T.; Laube, J.; Heinze, T.; Kulicke, W.-M. Properties and Flocculation Efficiency of Highly Cationized Starch Derivatives. Starch Stärke 2006, 58, 161-169. [CrossRef]

25. Aly, A.A. Preparation, Characterization and Evaluation of Anionic Starch Derivatives as Flocculants and for Metal Removal. Starch Stärke 2006, 58, 391-400. [CrossRef]

26. Pant, B.R.; Jeon, H.-J.; Song, H.H. Radiation cross-linked carboxymethylated starch and iron removal capacity in aqueous solution. Macromol. Res. 2011, 19, 307-312. [CrossRef]

27. Ekebafe, L.O. Removal of heavy metals from aqueous media using native cassava starch hydrogel. Afr. J. Environ. Sci. Technol. 2012, 6, 6. [CrossRef]

28. Soto, D.; Urdaneta, J.; Pernía, K.; León, O.; Muñoz-Bonilla, A.; Fernández-García, M. Heavy metal (Cd2+, Ni2+, Pb2+and Ni2+) adsorption in aqueous solutions by oxidized starches. Polym. Adv. Technol. 2014, 26, 147-152. [CrossRef]

29. United Nations Environment Programme, Chemical Branch, DTIE. Final Review of Scientific Information on Lead-Version of December 2010. 2010. Available online: https://wedocs.unep.org/handle/20.500.11822/27635 (accessed on 15 February 2021).

30. Abbas, A.; Al-Amer, A.M.; Laoui, T.; Al-Marri, M.J.; Nasser, M.S.; Khraisheh, M.; Atieh, M.A. Heavy metal removal from aqueous solution by advanced carbon nanotubes: Critical review of adsorption applications. Sep. Purif. Technol. 2016, 157, 141-161. [CrossRef]

31. Ahmed, M.J.K.; Ahmaruzzaman, M. A review on potential usage of industrial waste materials for binding heavy metal ions from aqueous solutions. J. Water Process. Eng. 2016, 10, 39-47. [CrossRef]

32. Das, A.; Bar, N.; Das, S.K. Pb(II) adsorption from aqueous solution by nutshells, green adsorbent: Adsorption studies, regeneration studies, scale-up design, its effect on biological indicator and MLR modeling. J. Colloid Interface Sci. 2020, 580, 245-255. [CrossRef]

33. Ali, H.; Khan, E. Bioaccumulation of non-essential hazardous heavy metals and metalloids in freshwater fish. Risk to human health. Environ. Chem. Lett. 2018, 16, 903-917. [CrossRef]

34. Church, B.G.; Van Sprang, P.A.; Chowdhury, M.J.; Deforest, D.K. Updated species sensitivity distribution evaluations for acute and chronic lead toxicity to saltwater aquatic life. Environ. Toxicol. Chem. 2017, 36, 2974-2980. [CrossRef]

35. Air Quality Guidelines for Europe, 2nd ed.; WHO: Geneva, Switzerland; Regional Office for Europe: Copenhagen, Denmark, 2000; ISBN 978-9-28-901358-1.

36. Caravati, E.M. Medical Toxicology, 3rd ed.; Lippincott, Williams \& Wilkins: Philadelphia, PA, USA, 2004; ISBN 978-0-7817-2845-4.

37. Cleveland, L.M.; Minter, M.L.; Cobb, K.A.; Scott, A.A.; German, V.F. Lead hazards for pregnant women and children: Part 1: Immigrants and the poor shoulder most of the burden of lead exposure in this country. Part 1 of a two-part article details how exposure happens, whom it affects, and the harm it can do. Am. J. Nurs. 2008, 108, 40-49. [CrossRef]

38. Moiseenko, T.I.; Gashkina, N.A. Biogeochemistry of Cadmium: Anthropogenic Dispersion, Bioaccumulation, and Ecotoxicity. Geochem. Int. 2018, 56, 798-811. [CrossRef]

39. Hsu, L.-C.; Huang, C.-Y.; Chuang, Y.-H.; Chen, H.-W.; Chan, Y.-T.; Teah, H.-Y.; Chen, T.-Y.; Chang, C.-F.; Liu, Y.-T.; Tzou, Y.-M. Accumulation of heavy metals and trace elements in fluvial sediments received effluents from traditional and semiconductor industries. Sci. Rep. 2016, 6, 34250. [CrossRef]

40. Hutton, M. Sources of cadmium in the environment. Ecotoxicol. Environ. Saf. 1983, 7, 9-24. [CrossRef]

41. Pavlaki, M.D.; Araújo, M.J.; Cardoso, D.N.; Silva, A.R.R.; Cruz, A.; Mendo, S.; Soares, A.M.V.M.; Calado, R.; Loureiro, S. Ecotoxicity and genotoxicity of cadmium in different marine trophic levels. Environ. Pollut. 2016, 215, 203-212. [CrossRef]

42. Hartwig, A. Cadmium and Cancer. Metal Ions Life Sci. 2012, 11, 491-507. [CrossRef]

43. Godt, J.; Scheidig, F.; Grosse-Siestrup, C.; Esche, V.; Brandenburg, P.; Reich, A.; Groneberg, D.A. The toxicity of cadmium and resulting hazards for human health. J. Occup. Med. Toxicol. 2006, 1, 22. [CrossRef]

44. Mathy, P. (Ed.) Air Pollution and Ecosystems; Springer: Dordrecht, The Netherlands, 1988; ISBN 978-94-010-8276-1. 
45. Rosseland, B.O.; Eldhuset, T.D.; Staurnes, M. Environmental effects of aluminium. Environ. Geochem. Health 1990, $12,17-27$. [CrossRef]

46. Shinzato, M.C.; Hypolito, R. Effect of disposal of aluminum recycling waste in soil and water bodies. Environ. Earth Sci. 2016, 75, 1-10. [CrossRef]

47. Hashimoto, Y.; Sekine, Y.; Otoshi, T. Atmospheric aluminum from human activities. Atmos. Environ. Part B Urban Atmos. 1992, 26, 295-300. [CrossRef]

48. Igbokwe, I.O.; Igwenagu, E.; Igbokwe, N.A. Aluminium toxicosis: A review of toxic actions and effects. Interdiscip. Toxicol. 2019, 12, 45-70. [CrossRef]

49. Gensemer, R.W.; Playle, R.C. The Bioavailability and Toxicity of Aluminum in Aquatic Environments. Crit. Rev. Environ. Sci. Technol. 1999, 29, 315-450. [CrossRef]

50. Choksi, P.M.; Joshi, V.Y. Adsorption kinetic study for the removal of nickel (II) and aluminum (III) from an aqueous solution by natural adsorbents. Desalination 2007, 208, 216-231. [CrossRef]

51. Gonzalez, M.H.; Souza, G.B.; Oliveira, R.V.; Forato, L.A.; Nóbrega, J.A.; Nogueira, A.R.A. Microwave-assisted digestion procedures for biological samples with diluted nitric acid: Identification of reaction products. Talanta 2009, 79, 396-401. [CrossRef] [PubMed]

52. Nilsson, G.S.; Gorton, L.; Bergquist, K.-E.; Nilsson, U.J. Determination of the Degree of Branching in Normal and Amylopectin Type Potato Starch with1H-NMR Spectroscopy Improved resolution and two-dimensional spectroscopy. Starch Stärke 1996, 48, 352-357. [CrossRef]

53. Langmuir, I. The constitution and fundamental properties of solids and liquids. Part I. solids. J. Am. Chem. Soc. 1916, 38, 2221-2295. [CrossRef]

54. Sips, R. On the Structure of a Catalyst Surface. J. Chem. Phys. 1948, 16, 490-495. [CrossRef]

55. Dubinin, M.M. The Equation of the Characteristic Curve of Activated Charcoal. Proceedings of the USSR Academy of Sciences 1947, 55, 327-329.

56. Kamga, F.T. Modeling adsorption mechanism of paraquat onto Ayous (Triplochiton scleroxylon) wood sawdust. Appl. Water Sci. 2018, 9, 1. [CrossRef]

57. Foo, K.Y.; Hameed, B.H. Insights into the modeling of adsorption isotherm systems. Chem. Eng. J. 2010, 156, 2-10. [CrossRef]

58. Cael, J.J.; Koenig, J.L.; Blackwell, J. Infrared and Raman spectroscopy of carbohydrates. Part VI: Normal coordinate analysis of V-amylose. Biopolymers 1975, 14, 1885-1903. [CrossRef]

59. Cael, S.J.; Koenig, J.L.; Blackwell, J. Infrared and raman spectroscopy of carbohydrates. Carbohydr. Res. 1973, $29,123-134$. [CrossRef]

60. Kizil, R.; Irudayaraj, J.; Seetharaman, K. Characterization of Irradiated Starches by Using FT-Raman and FTIR Spectroscopy. J. Agric. Food Chem. 2002, 50, 3912-3918. [CrossRef] [PubMed]

61. Kuakpetoon, D.; Wang, Y.-J. Locations of hypochlorite oxidation in corn starches varying in amylose content. Carbohydr. Res. 2008, 343, 90-100. [CrossRef] [PubMed]

62. Zhang, Y.-R.; Wang, X.-L.; Zhao, G.-M.; Wang, Y.-Z. Preparation and properties of oxidized starch with high degree of oxidation. Carbohydr. Polym. 2012, 87, 2554-2562. [CrossRef]

63. Liu, Y.; Yang, L.; Ma, C.; Zhang, Y. Thermal Behavior of Sweet Potato Starch by Non-Isothermal Thermogravimetric Analysis. Materials 2019, 12, 699. [CrossRef]

64. Liu, X.; Wang, Y.; Yu, L.; Tong, Z.; Chen, L.; Liu, H.; Li, X. Thermal degradation and stability of starch under different processing conditions. Starch Stärke 2012, 65, 48-60. [CrossRef]

65. Liu, X.; Yu, L.; Xie, F.; Li, M.; Chen, L.; Li, X. Kinetics and mechanism of thermal decomposition of cornstarches with different amylose/amylopectin ratios. Starch Stärke 2010, 62, 139-146. [CrossRef]

66. Soliman, A.A.A.; El-Shinnawy, N.A.; Mobarak, F. Thermal behaviour of starch and oxidized starch. Thermochim. Acta 1997, 296, 149-153. [CrossRef]

67. Guidelines for Drinking-Water Quality, 4th ed.; World Health Organization: Geneva, Switzerland, 2017; ISBN 978-92-4-154995-0.

68. Al-Ghouti, M.A.; Da'ana, D.A. Guidelines for the use and interpretation of adsorption isotherm models: A review. J. Hazard. Mater. 2020, 393, 122383. [CrossRef] [PubMed]

69. Bundesministerin der Justiz und für Verbraucherschutz-Trinkwasserverordnung, Anlage 2 (zu § 6 Absatz 2): TrinkwV, 2019. 